\title{
Farmland Fragmentation, Farmland Consolidation and Food Security: Relationships, Research Lapses and Future Perspectives
}

\author{
Pierre Damien Ntihinyurwa $*$ (D) and Walter Timo de Vries
}

check for updates

Citation: Ntihinyurwa, P.D.; de Vries, W.T. Farmland Fragmentation, Farmland Consolidation and Food Security: Relationships, Research Lapses and Future Perspectives. Land 2021, 10, 129. https://doi.org/ $10.3390 /$ land10020129

Academic Editors: Kwabena Asiama and Hualou Long

Received: 1 December 2020

Accepted: 25 January 2021

Published: 29 January 202

Publisher's Note: MDPI stays neutral with regard to jurisdictional claims in published maps and institutional affiliations.

Copyright: (c) 2021 by the authors. Licensee MDPI, Basel, Switzerland. This article is an open access article distributed under the terms and conditions of the Creative Commons Attribution (CC BY) license (https:// creativecommons.org/licenses/by/ $4.0 /)$
Chair of Land Management, Department of Aerospace and Geodesy, Technische Universitaet Muenchen (TUM), Arcisstrasse 21,80333 Munich, Germany; wt.de-vries@tum.de

* Correspondence: pdamien.ntihinyurwa@tum.de

Abstract: Farmland fragmentation and farmland consolidation are two sides of the same coin paradoxically viewed as farmland management tools. While there is a vast body of literature addressing the connections between farmland fragmentation and farmland consolidation on the one hand and agriculture production and crops diversification on the other hand, their relationship with variations in food security is still under-explored. This challenges policy makers about whether and how to devise policies in favor of fragmentation conservation or defragmentation. Therefore, drawing on the multiple secondary data and the deductive logical reasoning through an integrative conceptcentric qualitative approach following the rationalist theory, this study critically reviews and analyses the existing body of literature to identify how farmland fragmentation versus defragmentation approaches relate to food security. The goal is to develop and derive an explicit model indicating when, where, how and why farmland fragmentation can be conserved or prevented and controlled for food security motives as a novel alternative comprehensive scientific knowledge generation, which could guide and inform the design of future research and policies about farmland fragmentation management. The findings show that both fragmentation and consolidation variously (positively and negatively) impact on food security at different (macro, meso and micro) levels. While farmland fragmentation is highly linked with food diversification (food quality), acceptability, accessibility, and sovereignty at the local (household and individual) levels, farmland consolidation is often associated with the quantity and availability of food production at the community, regional and national levels. Theoretically, the best management of farmland fragmentation for food security purposes can be achieved by minimizing the problems associated with physical and tenure aspects of farmland fragmentation along with the optimization of its potential benefits. In this regard, farmland consolidation, voluntary parcel exchange and on-field harvest sales, farmland realignment, and farmland use (crop) consolidation can be suitable for the control of physical fragmentation problems under various local conditions. Similarly, farmland banking and off-farm employment, restrictions about the minimum parcel sizes subdivision and absentee owners, joint ownership, cooperative farming, farmland use (crop) consolidation, agricultural land protection policies, and family planning measures can be suitable to prevent and minimize farmland tenure fragmentation problems. On the other hand, various agriculture intensification programs, agroecogical approaches, and land saving technologies can be the most suitable strategies to maximize the income from agriculture on fragmented plots under the circumstances of beneficial fragmentation. Moreover, in areas where both rational and defective fragmentation scenarios coexist, different specific strategies like localized and multicropping based land consolidation approaches in combination with or without agriculture intensification programs, can provide better and more balanced optimal solutions. These could simultaneously minimize the defective effects of fragmentation thereby optimizing or without jeopardizing its potential benefits with regard to food security under specific local conditions.

Keywords: farmland fragmentation; farmland consolidation; food security; food sovereignty; agroecology; integrative review 


\section{Introduction}

Farmland fragmentation has generally been considered as negative for agricultural production and food security and equivalent to the increase in production costs leading to farm inefficiency [1-11]. Consequently, most contemporary agricultural land policies aim to reduce fragmentation through land consolidation as a panacea to this quandary [12-18]. Besides the classical land consolidations programs, other instruments such as land banking [19-21], voluntary parcel exchange, land restrictions, cooperative farming, and land use consolidation (LUC) in Rwanda and Malawi [11,22-27] have been applied in some specific areas and situations. The success of each strategy depends on local conditions of a country and specific management and governance factors, since the strategy which works well in one country might not succeed in another [11]. Such idiosyncrasies necessitate each time a careful and substantive assessment of how and where farmland fragmentation patterns (forms, causes and both problematic and beneficial impacts) are similar or different. This assessment similarly applies to the success requirements and operational conditions of farmland fragmentation management strategies (as specific farmland management instruments) and their anticipated impacts prior to their transfer between countries $[11,12,16,28]$. The documented experience shows that the disregard of local conditions when designing and implementing land consolidation programs in sub Saharan Africa (Kenya, Malawi, Rwanda, Tanzania) and India led to failures and unintended harmful consequences in some areas [11,12,24,29-35].

On the other hand, there are counter arguments which consider farmland fragmentation as a demand-driven farmer's choice and strategy for risk management, exploitation of multiple ecological zones, labor bottlenecks management and self-sufficiency or independency in food production in subsistence communities through crops diversification for household food security $[6,31,33,36-42]$. These advocates argue that not all land fragmentation forms are equally problematic or defective. There might indeed be situations where the benefits of fragmentation outweigh the costs of consolidation, especially when it comes to areas which are overpopulated by communities relying on self-subsistence (agroecological) agriculture and/or mountainous characterized by diverse crop-growing conditions, socioecological heterogeneities and small farm sizes [11]. In such cases, fragmentation would be more favorable to support the management and mitigation of food production and market risks for the motives of local food security through its components of quality, accessibility, quantity and sustainability $[4,11,30,31,43-45]$ and food sovereignty [46]. For these research scholars, a strategy which favors diverse and multi-cropping systems (polyculture) under varying crop-growing conditions manages better the risks of total crops failure and production loss resulting from the consequences of the ever-increasing climate change scenarios (manifested in changes in rainfall patterns and temperatures) leading to environmental hazards (droughts, floods, winds, etc), diseases outbreak, and food price fluctuations, than a mono-cropping systems-based one (monoculture) [11,33]. Furthermore, being one of the key agroecological principles and elements, the spatial and temporal crops diversification at both field/plot, farm and landscape levels increases the resilience of local farmers against various climate change, prices fluctuations and other global risks thereby acting as the sustainable strategy for achieving food diversity, self-sufficiency in the production of culturally acceptable food diets and food sovereignty as the local approach of achieving food security [46-48]. Hence, farmland fragmentation in this situation is rather viewed as a rational choice which adapts to the environmental variations and generates local food security than a drawback [11]. Moreover, in the line of disheartening land consolidation initiatives, various studies over time disclosed negative correlations between farm sizes and crop yields when labor market management conditions are unfavorable $[11,31,49,50]$. According to Ntihinyurwa and de Vries [11], this stance explains why farmland fragmentation persists, and the choice dilemma of farmers about fragmentation conservation for its positive sides and/or its prevention and banishment for its negative sides, in spite of various consolidation initiatives to combat it. In this respect, de Vries and Chigbu [51] and Ntihinyurwa and de Vries [11] posit that both land fragmentation and land consolidation 
are equally responsible land management instruments, given the circumstances in which they are carried forward.

As part of the same debate, there exist various contrasting social, economic, and ecological theoretical constructs and models, which favor, explain and support the claims of each side, i.e., deriving and proving the benefits of land fragmentation or of land consolidation. On land consolidation side, Ntihinyurwa and de Vries [11] highlight for example the economies of scale theory which states that farm size and crops yield or output are positively related [17,52], the Gestalt theory stipulating that the whole is greater than the sum of its parts [53], along with the Malthusian theory which stipulates the existence of an inverse relationship between the population growth and food supply [54-56]. On the other hand, the economies of scope theory asserting that the volume of production is the result of many heterogeneous factors $[30,31,57]$, the complexity theory which argues for adaptation to emerging unpredictable complex phenomena [58-60], the ecological resilience theory which highlights the role and relevance of biodiversity conservation as an adaption to nature shocks $[61,62]$, the agroecology stipulating the crops diversification, resilience to natural shocks, and responsible governance of land and natural resources [47,48], and the Boserup's theory which stipulates the existence of a proportional relationship between the population growth and agriculture intensification $[55,56,63]$, support land fragmentation position. This polarized duality poses a crucial dilemma to policy makers and research scholars about whether they should devise and advise policies in favor of defragmentation (consolidation) or fragmentation conservation [11]. As stated by Ntihinyurwa and de Vries [11], this dilemma sometimes leads to the design of irrelevant farmland fragmentation control strategies which overlook the idiosyncrasies of specific fragmentation scenarios and its both contextual problems and benefits, and as a consequence derive disputed results leading to the failures.

Despite the subjectivity and the contradictions of various studies in literature, none of them has previously attempted to reconcile the above polarized views about farmland fragmentation and consolidation, and devise an explicit comprehensive relationship between these two concepts and food security as an end result instead of the existing focus on agriculture production and food quantity, since food security goes beyond the quantity. Chigbu et al. [32], Maxwell and Smith [64], Pinstrup-Andersen [65], Manjunatha et al. [66], Ntihinyurwa et al. [33], and Ntihinyurwa and de Vries [11] argue that although the popular logic is that land consolidation (especially due to increased farm size and reduced distances) has direct positive effects on increasing food security by boosting food production from conventional agriculture, this makes sense when food security is viewed from the lens of quantity. However, food security is much beyond the quantity of food production. It has the quality, accessibility, utilization, acceptability, sustainability, and sovereignty perspectives which can be achievable even under land fragmentation scenarios $[11,32,33,46,67]$. It is about more than growing enough food, since it implies the demand for it as well as the supply, the quality as well as quantity, an adequate diet (culturally acceptable quality and quantity meeting the local food preferences and needs) today and assurance of one tomorrow [11,32,33,46,54,65]. Following Sen's food entitlement theory [68], food security is achieved when everyone has access to regular, safe, nutritious and enough food $[11,32,65,69]$. For the advocates of food sovereignty, food security is achieved when local peasants have self-sufficiency in the production of their own food based on their cultural food preferences through local and sustainable agroecological approaches $[46,70]$. Furthermore, only few sporadic studies such as Bentley [30], Blarel et al. [31], Abubakari et al. [12], Kadigi et al. [50], Ntihinyurwa et al. [33], and Ntihinyurwa and de Vries [11] explicitly show when, where, how, and why one should keep fragmentation or opt for consolidation approaches, thereby calling for more comprehensive and holistic studies about this subject. In light of these arguments, there is a need to identify and compare categories and attributes of farmland fragmentation scenarios. For each of such scenarios one can describe which causes their constitution have, their impacts (positive and nega- 
tive) on external variables like food security, and which control strategies would be most appropriate to them.

To address this specific research lapse and respond to these research calls, this study aims to:

* critically review (by exploring and synthesizing) the existing documented conceptual relationships between farmland fragmentation and its control interventions (including land consolidation), and food security;

* identify the knowledge gaps and openings for further research;

* reconceptualize the relationships between farmland fragmentation, its control strategies, and food security;

* propose a new theoretical model of farmland fragmentation management which may better help policy makers than current subjective and disaggregated ones, and guide and inform future solutions-oriented and evidence-based studies about appropriate and suitable alternatives for dealing with farmland fragmentation.

It explicitly results in a substantive explanation of different farmland fragmentation scenarios, the conditions under which they become defective or beneficial, and proposes the suitable potential strategies for their sustainable management under various specific circumstances. Moreover, the development and comparison of farmland fragmentation scenarios and food security extends the existing debate about farmland fragmentation and consolidation, and multiple UN sustainable development goals, namely SGDs 1, 2, 12, 13 \& 15 , versus the global trends towards market-oriented agriculture. Specifically, SDGs 1.4 and 2.3 address land rights and how farmers own, access, secure and control land resources among all the heirs; SDG 12.2 refers to the sustainable management and efficient use of natural resources (including land); the diversification of crops in different fragmented and scattered areas with diverse growing conditions as an adaptive strategy (climate smart, agroecological or resilient agriculture) to the ongoing new global challenging realities of climate change and the core of SDGs $2.4,5 ; 13.1$ to end hunger and malnutrition resulting from food insecurity, is addressed by SDG 2.1, 2, 3, 4 \& 5); and the agrobiodiversity and ecosystems conservation through the protection of their natural habitats on land comes as focus of SDG 15.3,4,5 \& 9), in the framework of the Agenda 2030 [11,71]. The decisions about farmland use either in fragmented or consolidated forms can be most directly linked with these five SDGs whose specific targets capture the sustainable land management (ownership and use) and climate change adaption and mitigation, as key factors of sustainable agriculture production and food security to end hunger, malnutrition and poverty, even though land management as a scientific discipline may be connected with all the SDGs [11]. Since the terms of land fragmentation, land consolidation, and food security are variously conceptualized in different contexts, scientific disciplines and levels of analysis, in this article, only their meaning in the context of agriculture production at all levels is followed. The focus is given to the concept of food security from the lens of agriculture-based food stuffs, with little attention on the animal-based ones for the purpose of nutritional balance and food quality. Irrespective of the spatial and temporal limitations, only the literature about this topic in English language is considered.

The article is shaped in the following structure: The first section introduces the concepts of farmland fragmentation, farmland consolidation, and food security. The second section addresses the methodology of the literature identification, review, analysis, synthesis and reconceptualization. The subsequent third section categorizes and discusses farmland fragmentation scenarios and how these relate to their existing generic control (management) strategies (instruments) and interventions. Thereafter in fourth section, the concept of food security is discussed, and its relationships with farmland fragmentation and farmland consolidation approaches are assessed and synthesized. This section subsequently derives the new model of farmland fragmentation management and the reconceptualized relationships which are discussed and motivated in Section 5. Finally, the conclusions and implications of the study for further research and policies are drawn. 


\section{Methodology}

\subsection{Research Approach and Boundaries}

As an integrative review article (relying only on secondary data), this research opts for an integrative concept-centric qualitative approach which draws on the deductive logical reasoning following the rationalist theory through the exploratory research design, to create new scientific knowledge from the existing general facts in literature and inform future research and policies [11,72-75]. This approach is considered by Ntihinyurwa and de Vries [11] and Ntihinyurwa and de Vries [75] as the most suitable research epistemology for this kind of study, since it deductively uses the researchers' own reasoning (abstract way of reasoning) without sensory experiences or empirical data to create novel scientific knowledge. The researchers use their own knowledge about the topic to critically analyze and synthesize the existing knowledge about different concepts, theories and principles, and deduct their own new and particular conceptualizations (models or frameworks) from the reviewed general facts [11,72-76]. Webster and Watson [74] and Torraco [73] argue that this approach fosters the critical review, analysis and synthesis of existing knowledge about the topic under research, with the objective of devising possible relationships among various research variables, identify knowledge gaps and contradictions, and seek opportunities for future research. The main aim of this approach is the re-conceptualization of the topic in a more understandable way for the guidance of future perspectives and expansion of the existing theories or creation of new knowledge in a particular scientific domain [11,72-76]. Hence, given the scope of the study of understanding various farmland fragmentation scenarios and proposing their suitable management strategies and interventions to achieve food security, only the literature about the forms, causes and impacts of agricultural land fragmentation and its alternative control measures across contexts and disciplines at all spatial levels was considered as a contextual boundary of the study, since the required information can mostly be derived from the relationships among these research variables. The use of multiple spatial levels of analysis is explained by the fact that farmland fragmentation itself is a multi-level phenomenon, whose causes, impacts as well as control strategies can be identified from the local (individual, household, family, village) to regional and national levels [11]. Spatial and temporal limitations (boundaries) were not considered throughout the review process for internal data validity purposes. This led to the review of both old and new geographically unlimited available literature materials on the topic, as a suitable method for this case of research approach which requires a comprehensive and broad literature. This review technique adopts a synthetic strategy of sense making which suggests the use of multiple cases and broad selection criteria to create a more comprehensive knowledge $[11,74,75,77]$. Nevertheless, for the purpose of preventing various conceptual divergences, misuse, and linguistic bias, both empirical (primary) and review (secondary) literature only in English language in which a large body of extensive literature on this topic exist $[11,75]$, was considered for this review. This approach was recently used in quite similar studies and contexts by Asiama et al. [29], Asiama et al. [28], Ntihinyurwa and de Vries [11], and Ntihinyurwa and de Vries [75]. The following subsection explains the processes and methods for literature identification (search, selection criteria and its sources, scientific repositories or databases), review, analysis and synthesis techniques, and the reconceptualization or modelling methods and procedures as summarized in the research design (see Figure 1). 


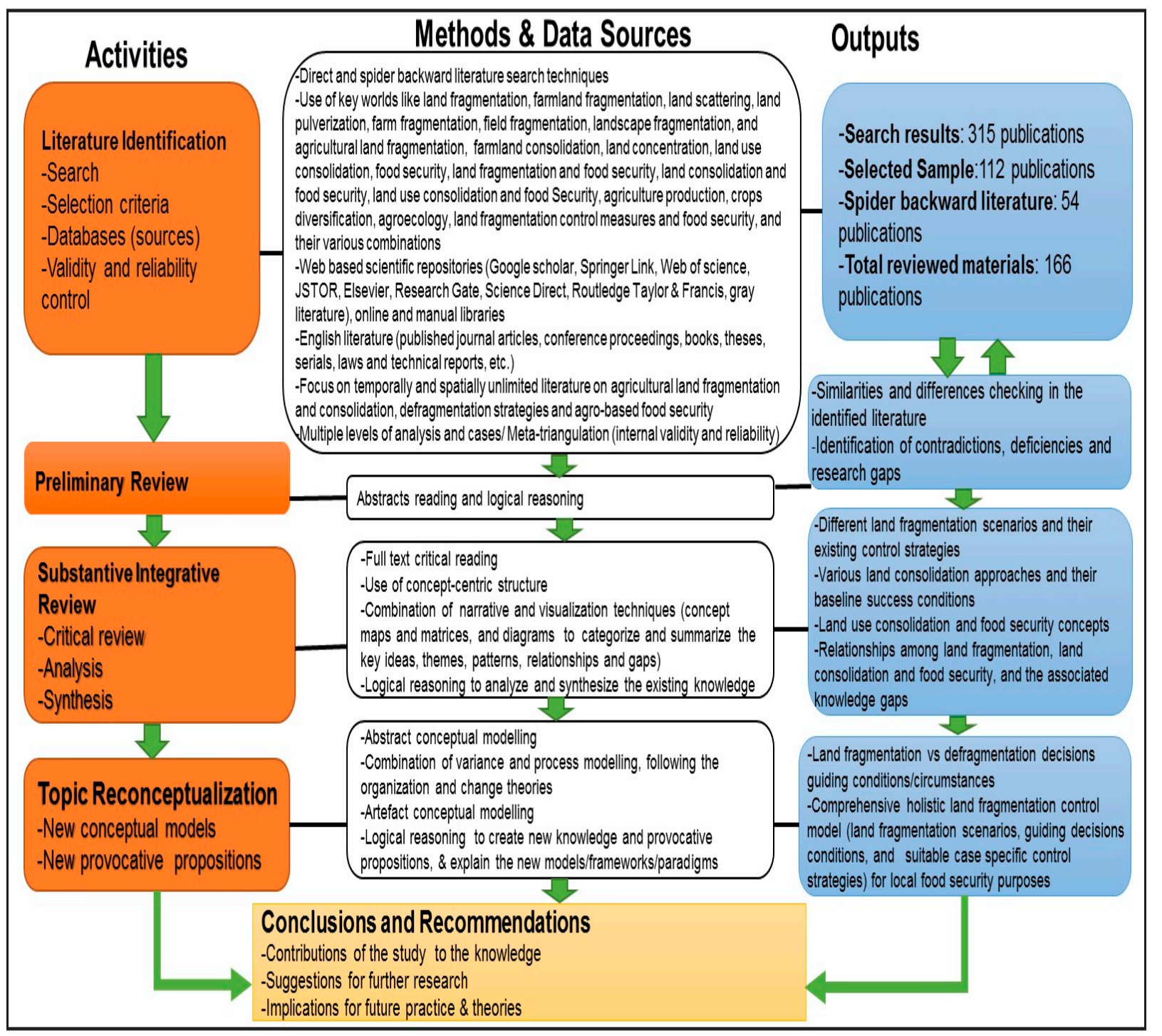

Figure 1. Overview of the research process and design. Source: Adapted from Ntihinyurwa and de Vries [11] and Ntihinyurwa and de Vries [75].

\subsection{Data Sources and Research Methods}

Once the boundaries of the literature were set up, we proceeded with the literature identification (search and selection). The following key words combinations were the basis for the search strategy: farmland fragmentation, farm fragmentation, land fragmentation, landscape fragmentation, field fragmentation, land pulverization, agricultural land fragmentation, land scattering, land fragmentation control measures, land consolidation, farmland consolidation, land concentration, land use consolidation (LUC), farm land use consolidation, crop consolidation, food security, farmland fragmentation and food security, farmland consolidation and food security, land use consolidation and food security, land banking and food security, agriculture production and food security, crops diversification and food security, land fragmentation control measures and food security, agroecology and food security, and agriculture intensification and food security. These key word combinations were chosen based on their closeness to the topic and the likelihood of generating the desired information. Individual instances of these key words and their diverse combinations were the systematic search strategies across different well-known web based scientific repositories (for soft documents) and the online and physical library visits (for hard documents) in English language (see Section 2.1 and Figure 1 for detailed 
search and selection criteria). These web-based scientific repositories include among others: Web of Science, Google Scholar, Springer Link, Research Gate, Routledge (Taylor \& Francis), JSTOR, and Journals websites. Additionally, throughout the literature search process, relevant grey literature (published and unpublished non-commercial literature materials) from various governmental and non-governmental multilateral and bilateral organizations and institutions (such as FAO, GLTN, USAID, IFPRI, World Bank Group, UN and UNHabitat amongst others) was taken into account. According to Webster and Watson [74], Torraco [73], Ntihinyurwa and de Vries [11], and Ntihinyurwa and de Vries [75], the use of multiple synonymous and diverse key words across many different data sources in literature identification provides a benefit of offering a large variety of documents about the topic for the motives of data and findings validity and authenticity. The search was nearly complete when no new concepts were found in the records set [11,73-75]. The literature identification process resulted in the retrieval of 315 written records including $292 \mathrm{soft}$ documents varying from published peer reviewed journal articles and review papers, magazine articles, books, book sections, conference proceedings, laws and acts, technical reports, theses to press releases and serials, and 23 hard documents from visited libraries. The screening and preliminary review of the search results was done through critically scanning all titles and abstracts of the retrieved literature materials taking into account the above-mentioned review boundaries (see Section 2.1 and Figure 1) and elimination of duplicates. This process resulted in the selection of 112 relevant materials eligible for a full text review.

In the light of the aim and the scope of the study, a concept-centric (thematic) approach was adopted as the most suitable organization strategy for integrative literature review, analysis and synthesis [11,72-75]. Following this approach, all the articles with similar claims and views were grouped together and categorized through the combination of textual (narrative) and visual representations [11,73-75]. In this regard, throughout the reading session, a concept matrix $[78,79]$ was developed to categorize different ideas and themes across various research variables encapsulating the concepts of farmland fragmentation, farmland consolidation, and food security in a more understandable, precise and narrow way. The content review consisted of both the analysis and synthesis of key and critical aspects of the research variables, and a listing and display of new relationships and research gaps [11,75]. During the review process, new seminal articles and frequently cited relevant references were identified and traced backward from their original materials using a spider backward literature search technique for further consideration in the review [11,75]. This technique resulted in the selection of 54 additional eligible documents for full text review, which therefrom generated the total number of 166 reviewed materials. In order to identify the strengths, weaknesses, deficiencies, contradictions, problematical situations and research gaps which need to be closed by the new knowledge [11,75], various farmland fragmentation scenarios and their existing control strategies were thoroughly reviewed, and their spotlighted relationships with food security critically analyzed using our existing knowledge about the topic through the logical reasoning following the rationalist theory [11,73-75]. This approach of conceptual reasoning is suitable for integrative theoretical studies which seek to analyze insights from past experiences and views for the preparation of future perspectives and guidance [11,72-75], and has been previously used by many research scholars in quite similar context with this one including McPherson [80], Bentley [30], Asiama et al. [29], Asiama et al. [28], Ntihinyurwa and de Vries [11], and Ntihinyurwa and de Vries [75]. The identified theoretical relationships and research gaps from the critical analysis were exhaustively summed-up in different diagrams and alternative models, or weaved together in a unique synthesis for a better presentation of the situation and basis for a reconceptualization of farmland fragmentation, farmland consolidation and food security nexuses. This also helped to inform the design of a new comprehensive and holistic conceptual thinking about farmland fragmentation management to support the achievement of the sustainable development goals (SDGs 1, $2,12,13$, and 15) within the existing climate change realities. An abstract conceptual mod- 
elling combining both variance and process graphical models in artefact format $[77,81]$ and textual models following the organization theory, theory of change, complexity theory and the soft systems methodology of thinking (SSM) $[59,60,82,83]$, and the dynamic systems theory [84-86], was used to develop a new model. This model shows different farmland fragmentation scenarios, their proposed specific managerial decisions and strategies under different conditions, and their hypothetical impacts on food security and other aspects of livelihoods. The logic conceptual reasoning approach $[74,87]$ combined with the reviewed theoretical foundations and documented empirical findings of the reviewed materials were used to justify various combinations and propositions of the model [75]. Finally, the implications of the new model to the existing knowledge and decision and policy makers were explained, and suggestions for future research to fill the newly identified gaps and empirically test the new relationships were derived $[11,72-74,76]$.

\section{Farmland Fragmentation Scenarios and its Management Strategies: Land Consolidation as a Controversial Multi-layered and Progressive Panacea to a Multidimensional Quandary}

The concept of farmland fragmentation may at first glance seem very complex, fluid and multidisciplinary, as it refers to both a spatial structure and a management strategy [75]. As a multidimensional concept, it has been variously and subjectively defined in the existing literature $[30,88]$. Some research scholars commonly define it as the situation where a single farm consists of numerous spatially separated (non-contiguous) small parcels often scattered over a wide area [2,4,30,37,75,88-93]. Igbozurike [94] provides a more holistic and objective conceptualization by defining it as the process by which a contiguous block of land is split into two or more parts [75]. It has been simultaneously described as a natural and socio-economic phenomenon that occurs at different spatial levels (parcel, farm, land block and landscape). Thus, its conceptualization and derived forms should draw from the existing relationship between land parcel (object) and people (subject) in land management paradigms [33,75]. Following this approach, any fragmentation in the physical characteristics of a land parcel as an object (size, use, shape, type, location) dictate the existence of different physical fragmentation forms [75]. Similarly, any fragmentation derived from the social relationships (rights, restrictions and responsibilities) between land parcel (object) and people (subject) implies the occurrence of various social or tenure fragmentation forms (both visible and hidden ownership and usership) at different spatial levels [75]. Moreover, the economic characteristics of land (value and market) often dictated by social and physical traits may also imply some fragmentation forms and scenarios. Therefore, referring to the study of Ntihinyurwa and de Vries [75], physical farmland fragmentation stands for any type of fragmentation in physical characteristics of land either internal or external at all spatial levels, while tenure fragmentation refers to any fragmentation form derived from the split in the social characteristics of land in terms of its relationships with people, irrespective of the exclusive internality and externality criteria. Hence, in this context, farm fragmentation (often referred to as internal or within farm fragmentation) denotes the situation when a single farm is physically split into many relatively small plots (parcels) either spatially dispersed or contiguous (physical fragmentation), or shared by many undocumented co-owners or co-users (hidden tenure fragmentation in terms of ownership or usership) [33,75]. On the other hand, according to Ntihinyurwa and de Vries [75], farmland fragmentation refers to the split of the farming structure in a relatively small land block or region into many small farms (visible and hidden tenure fragmentation in terms of ownership and usership), or into many small plots or parcels (physical fragmentation). When the split into many plots happens at the parcel level, this phenomenon is denoted as parcel or field fragmentation. The land value (social and economic) fragmentation and land market fragmentation exist when a land block is split into smaller subunits like land parcels and plots with different socio-physical peculiarities dictating the diversity in value and market of the land. Irrespective of various contradictory theories of Earth creation, it is obvious that the landscape is naturally fragmented (in soil type, size, location, shape, topography), which ontologically explains the existence of physical fragmentation at the landscape level 
as a natural phenomenon, independent of human activities and land-people relationship. This relationship is often defined at the parcel level $[95,96]$, which dictates the existence of physical, social (tenure), and economic fragmentation forms. Despite the dynamic nature of this fragmentation concept, King and Burton [97] and Ntihinyurwa and de Vries [75] assert that the above fragmentation forms can coexist in the same area at different levels, and its extent is determined by the local conditions in specific countries and areas [75]. This entails the existence of different possible generic and specific fragmentation scenarios from various combinations of its indicators [75]. Notwithstanding various conceptualizations of this fragmentation phenomenon from the socio-economic and physical perspectives and different subjective levels of analysis, all the analyzed literature materials have a commonality of referring to agriculture land fragmentation (see Ntihinyurwa and de Vries [75] for more details on various farmland fragmentation forms and scenarios).

The causes and impacts of farmland fragmentation in the literature have always been subject to contradictory and multidisciplinary debate by considering it either beneficial (voluntary) to farmers (as risk management strategy for household food security) or defective (derived from external imposition which leads to the reduction of farm efficiency through the increase of production costs) (see Ntihinyurwa and de Vries [11] and Ntihinyurwa et al. [33] for more details). However, recent studies revealed that its problematical and beneficial scenarios are dictated by a combination of local specific external conditions, varying from economic, socio-cultural, political, ecological, technical to environmental ones, which therefore similarly implies the variation of their management strategies $[11,12,17,18,30,33,90]$. According to [75], with reference to the problems linked with farmland fragmentation, its problematic forms can be categorized into four distinct groups: (i) farmland location or spatial fragmentation (problems of long distance between plots and farmstead); (ii) farmland size fragmentation (problems of small plots and farm sizes); (iii) farmland shape fragmentation (problems of shape irregularity), and (iv) farmland use fragmentation (problems of multiple mixed uses or multiculture).

Whether problematic or beneficial, agricultural land fragmentation needs a certain level of management for sustaining the quality and quantity of agriculture production for food security purposes in a given area. In this regard, various strategies have been developed over time to control this complex phenomenon. Demetriou [98] grouped them into three main categories as follows:

- Legal provisions and restrictions relating to inheritance, minimum size of parcel subdivision, joint ownership, absentee landowners, prevention of transfer to nonfarmers, leasing, and imposition of a maximum limit on the size of a holding to prevent the rational drivers of fragmentation phenomenon from worsening the situation.

- Land management approaches including land consolidation, land funds and land banking, voluntary parcel exchange, and cooperative farming to reverse and inhibit the harm of the existing fragmentation.

- Agricultural land protection policies which embrace the Purchase of Development Rights (PDR), the Transfer of Development Rights (TDR), and the Cluster Development Programs (CDP) in USA to prevent its use for other purposes or development activities like residential, commercial, etc. These are described below.

(a) Land Consolidation: Even though the concept of land consolidation has its roots in the medieval ages with the first initiative in the 1750's in Denmark as a social reform [4] and was implemented in different countries for millennia, there is no common definition for it, as it varies across contexts and by country with respect to the end goals and objectives. It is generally known as a process of arranging parcels together in order to make them more productive and reduce the adverse effects of fragmentation in agriculture $[4,19,98,99]$. In the German Land Consolidation Act (1976), it is considered as an instrument of improving production and working conditions in agriculture and forest lands as well as promoting the general use and development of land in rural areas and the living conditions of rural livelihood, through the re-arrangement of agricultural land by restructuring the shape, size, ownership and location of farmland parcels and forestry $[10,16,97,100-102]$. 
FAO [4] defines it as a land management activity that involves all the procedures for exchanging, rearranging, realigning, and expanding farm parcels in rural areas with the goal of increasing food productivity. In this context, the parcel boundaries, ownership, size and location of the land are restructured for its best use and management. Since the reallocation of new parcels as a core for land consolidation procedures is rather value than shape, use, size and location based, land valuation based on soil evaluation is considered as the basic activity which should be given a special attention and management to reduce the pace of resultant conflicts in this strategy [12,15-17,103-106]. Land consolidation started as a monofunctional concept with a single objective of improving agriculture production which is still kept in Scandinavian countries like Sweden (fastighetsreglering), Norway and Denmark. It gained its momentum in 1970s, and started to integrate other objectives of rural development like village renewal, landscape and natural resources management, and forests management afterwards $[16,20,107]$. It is currently implemented with success as a comprehensive rural development strategy in many western European countries like the Netherlands (ruilverkaveling), Germany (Flurbereinigung), France (remembrement), Luxembourg, Spain, Belgium, Switzerland and Austria, as well as Finland (uusjako), and in Asian countries like China, India, Nepal, South Korea and Japan, where it is embedded in large national and regional development programs $[16,101,102,107]$. Van der Molen et al. [20] argue that land consolidation also called concentration [39] as an ambivalent concept (instrument and principle) following different principles (parcel reallocation and improvement of physical conditions) has a common objective of making the parceling of one farm more compact (few contiguous parcels close to the homestead) and the farming structure in a given region denser (few farms per land block with higher average farm size), in order to create more operational and viable farm units. In this context, it is theoretically and commonly understood as a process of making the parceling of one farm or a farming structure of any region more compact with few parcels per farm or land block, and higher average parcel and farm sizes respectively $[4,16,18,20,108,109]$. FAO [4] advances that any modern land consolidation should follow the following principles:

- The objective should be to improve the rural livelihoods rather than only the primary production of agricultural products.

- The end result should be the whole community renewal through its sustainable economic and political development, and the protection and sustainable management of natural resources.

- The process should be participatory, democratic and community-driven not only in concept, but also in practice.

- The interventions should be to assist the community to define new uses for its resources and then reorganize the spatial components accordingly.

- The approaches should be comprehensive and cross-sectoral, integrating elements of rural and broader regional development including the rural-urban linkages.

Several other studies indicate that the local agricultural, economic, social, cultural, environmental, agroecological and political conditions of the area dictate the procedures, objectives and models of land consolidation in different countries, although the implementation principles remain the same everywhere $[12,13,16,18,19,28,33,110]$. They argue that the variations in local conditions make it necessary to allow the creation of different local versions or approaches of land consolidation, based on the available problematic land fragmentation forms and needs of rural local population. A successful consolidation approach of flat areas cannot necessarily apply in mountainous areas. This idea is guided by the FAO principles stipulating that a good land consolidation strategy must recognize the diversity of rural society and the non-problematic scenarios of land fragmentation $[4,111]$. This dictates the need for diverse local solutions, including keeping the beneficial fragmentation for crops diversification motives for food security and sovereignty, and risks and labor management under multiple agroecological zones [30]. In this vein, different land consolidation forms (approaches) have been developed over time. The most commonly known include the comprehensive, simplified, voluntary, individual, 
government-led, private company-dominated, and farmland use consolidation among others $[4,16,23,99,108,112,113]$ as described below:

$>$ Comprehensive land consolidation: It embraces the re-shaping and re-allocation of parcels together with a broad range of other measures and activities that support and promote the rural development $[4,16,114]$. Examples of such activities include extension services for rural communities, the village renewal, the construction of rural roads and water infrastructure, the co-construction and support to community based alternative agro-processing techniques, the erosion control measures, the construction and rehabilitation of irrigation and drainage systems, the creation of social infrastructure including sports grounds and other public facilities, along with the environmental protection and improvement measures including the designation of nature reserves $[4,16,114]$. This model prevailing in Germany and the Netherlands presents the drawback of taking too long in implementation, due to the complexity of involved activities and large coverage. It is mostly government-led, and somehow involves a certain level of compulsion in participation $[4,16,114]$. It is more effective when it is combined with land banking programs to counter the challenges of unwilling participants in order to enlarge the parcels and landholdings [4,16,114]. Although its implementation procedures vary from country to country, they generally involve the following phases: initiation or the design of the project (feasibility study); inventory of existing 3Rs (rights, restrictions and responsibilities like ownership, tenancies, easements, usufructs, mortgages and conflicts) and values over land (land valuation); elaboration of the detailed consolidation plan showing the new parcels layout and their reallocation which shall be presented to the public for claims consideration and accepted by all land owners before the final plan; implementation of the final plan and appeal proceedings; and finally a concluding phase in which the final records are produced $[4,16]$. Drawing from the recent study of Veršinskas et al. [114], the mandatory and majority-based (the decisions to compulsorily consolidate are based on the votes of the majority) land consolidation types fall in this category. The same study groups the consolidation process in this model in three phases of the feasibility phase, the re-allotment phase, and the registration and implementation phase. Notwithstanding its multifunctionality, when flexible and participatory, the comprehensive land consolidation can be subject to different changes and take different approaches to adapt it to the local collective needs and objectives, contrary to the government-centered one [115].

$>$ Simplified land consolidation: To overcome the challenges of long duration due to the complexity of activities in comprehensive consolidation models, the simplified land consolidation has been created to optimize the conditions in agricultural sector through the exchange or re-allocation of parcels, and the provision of additional lands from land banks $[4,16]$. These simplified projects are often combined with minor public works like the rehabilitation of infrastructure and sometimes the provision of minor facilities with the primary objective of improving the working conditions in agriculture. They are mostly implemented on a small coverage and follow similar but simplified procedures as comprehensive land consolidation $[4,16]$. This is the case of German special land consolidation proceedings and Swedish forest re-allotment projects $[4,16]$.

$>$ Voluntary group consolidation: It is based on the mutual agreement among close land owners to consolidate their adjacent plots with no element of compulsion in some countries [4]. Since the consolidation is entirely voluntary, during the process, all participants must fully agree with the proposed project $[4,16,114,116]$. In the light of this, such voluntary projects tend to be small, usually with less than ten participants and best suited to address small and localized fragmentation problems with less harm to the environment $[4,16,28]$. In Denmark, this option is most common and almost all land consolidation projects are carried out in a completely voluntary process, and typically involve the negotiations with up to 50 land owners, even though some 
few projects may involve about 100 participants [4]. Countries like Lithuania and others are currently following this approach $[4,16,28,116]$.

$>$ Individual consolidation: In this form, the consolidation of holdings takes place on an informal and sporadic basis without a direct involvement of the state and the provision of public facilities $[4,117,118]$. Nevertheless, the state can play a significant role in encouraging consolidations that improve agriculture by promoting instruments such as joint land use agreements like cooperative farming, scattered parcels exchanges among farmers to create compact farms, farmland use or crop consolidation, and leasing and retirement schemes [4,16,117].

$>$ Land Use Consolidation (LUC) or Consolidation of crops: LUC program also known as Farm Land Use Consolidation in USAID reports, and land consolidation in the Ministerial order on land consolidation models in Rwanda (2010), refers to the consolidation of the use of farmlands where all farmers with close parcels grow one same crop in a synchronized way up to the minimum size of 5 ha from the 8 priority food crops (maize, beans, wheat, rice, Irish potatoes, banana, cassava and soybeans) chosen by the government at the national level based on the Agro Ecological Zones (AEZ) of the country $[23,26,32,33,117,119]$. Contrary to other land consolidation programs, the individual land rights in LUC remain intact $[32,33,117]$. It is a national program implemented in the whole country as one of the pillars of the Crop Intensification Program (CIP) with the objectives of increasing agricultural production, improving the living conditions in rural areas, and meeting food security [23,26,28,32,33,117]. Huggins [24] and Pritchard [34] call it "Crop Consolidation". Similar programs have been previously documented in Malawi, and in Europe in case of viniculture consolidation programs $[16,26,120]$.

Although land use consolidation (LUC) is conceptually considered as a special form or approach of land consolidation, from the practical perspective in Rwanda and Western Europe, the two terms do not have much in common in terms of activities involved. While in land consolidation the sizes, shapes, boundaries, locations and ownership of land parcels are rearranged with no control on the use, and the parcel values kept intact, only the use of farmlands for priority crops is consolidated in the case of land use consolidation in Rwanda, with all the other attributes remaining unchanged. Nevertheless, the two strategies share the same objective of improving agriculture production and the rural livelihoods, even though LUC has been criticized to only lead to the monoculture (mono-cropping) system resulting in food insecurity at the household level in case of climate change, natural shocks, and market imperfection scenarios [24,32-34,119,121]. Furthermore, one could wonder whether it is the most suitable strategy to the problematic land fragmentation scenarios in Rwanda, considering the heterogeneous local social, economic, physical and ecological conditions of the country. In support to this doubt, recent findings of Isaacs et al. [122] revealed the benefits of improved intercropping system to outperform the ones from the government-led mono-cropping through LUC in terms of household food security and risks management insurance. Niyonzima [123] found that the national farming programs including LUC encouraging the monoculture and environmental policies have failed to address the local farmers needs in the Eastern Province of Rwanda mainly due to the market imperfections, thereby recommending the support to mixed farming systems as a promising solution for agricultural production and household food security concerns. Therefore, contrary to the studies of Laepple [120], Vitikainen [16], Musahara et al. [26], and Asiama et al. [28], we claim that there is no rationale for considering land use consolidation as part of conventional land consolidation approaches, rather a particular type of agricultural land use management, and a tool for farmland management like land consolidation as well.

With regard to the emergence of new issues in the implementation of government-led land consolidation projects in China, a new approach of company-dominated pattern of land consolidation programs [113] has been developed as an efficient strategy for both physical and tenure fragmentation problems. In this approach, the private companies act as land bank institutions and acquire large lands through the negotiations-based expropriation 
programs from small farmers to create big land funds which could later be farmed as single consolidated viable operational units, or leased to big farmers [113]. The commonality of these consolidation models is that most of them are regulated and facilitated by land professionals [114].

Whereas the success conditions of different land consolidation approaches vary from country to country, the common key feature is that the relative economic value and ownership of land should be kept constant before and after consolidation following the surrogate principle of land valuation, with the benefits from such consolidation exceeding the costs of its establishment [16,30]. Similarly, Van Dijk [18], Hartvigsen [19], Asiama et al. [28], and Asiama et al. [17] argue in their respective studies on Central and Eastern Europe and Ghana, that the economic value of land should exceed its social value (perfect land market leading to high land mobility) as a key precondition for success of land consolidation programs. In this regard, various researchers have highlighted and documented the general baseline conditions which need to be considered before the development of any specific land consolidation approach in an area $[4,12,18,19,28,30,107,108,124-127]$. These include:

-Land tenure system: It dictates the decisions about the parcels reallocation process as a core for land consolidation. The customary or community land tenure system has been considered to be an obstacle to this activity, since farmers only have use rights over their lands, with no allocation rights without the consent of the chiefs who hold the custodian rights (allodial title) to control and allocate the use of land on behalf of their community $[12,17,28]$. Furthermore, in customary tenure systems, land is considered as a sacred property of the family which should be preserved for future generations (ibid). This increases the social attachment to land and social land value, which in turn reduces land mobility as an obstacle to land reallocation and land market $[18,19]$. Likewise, the absentee owners in case of usership fragmentation obstruct the reallocation process since they do not find any direct interests from consolidation. On the other hand, the users (tenants) do not have the ownership and allocation rights, which decreases their willingness to invest in long term projects like land consolidation $[11,18]$. The failure of previous land consolidation attempts in customary lands has been attributed to the focus on technical and economic aspects, thereby ignoring this important social benefit [28]. Asiama et al. [17] found that the exchange of parcels in the Ghanaian customary lands is only possible among family members within the same community, with very limited mobility among communities. For this, the statutory individual private tenure system with individual ownership rights has been pinpointed as a suitable success condition for modern land consolidation projects by facilitating the decision making about reallocation with consent from one or few owners $[12,18,19,28,104]$.

-Economic status and land market: They dictate the approach of land consolidation to be adopted, and the reallocation process. A perfect land market increases the economic value of land (land as an economic commodity), which in turn reduces the social attachment to land (social value), thereby easing land mobility and the reallocation of land during land consolidation. This is explained by the theory of land mobility stipulating that when the economic value of land is higher than its social value, the mobility of land through any kind of transfer increases $[18,28,109]$. Furthermore, the macro economic conditions have been found to facilitate the adoption of modern comprehensive land consolidation approach, which needs considerable financial capacities from both farmers and the state, while the subsistence economies favor more simplified and cheap approaches [16,28].

-Willingness of farmers to participate: This is crucial for the success of any land consolidation project and the type of approach to follow. It is dictated by land psychology (i.e., sense of social attachment to land), economic status, land availability, and land market. From a rational perspective, farmers accept to participate when the economic benefits from the project outweigh the costs and its social ones. Participation also relates to the degree to which project managers have an affinity with the area [128]. FAO [4] suggests that land consolidation process should be demand-driven by farmers, and the government should intervene to assist them in choosing the suitable approaches to their land use needs. 
In case a big number of farmers accept the participation, the reluctance of few farmers is overcome by a certain level of compulsion in some cases and the expropriation processes through land banking. The subsistence farmers in risks prone areas with scarce land and absentee owners often resist land consolidation programs which rearrange the ownership structure, sizes, locations and boundaries, due to the fear of losing their original rights over land $[4,12,17,30,97,129]$.

-Availability of land banks: Although not a sine qua non condition for all land consolidation projects, it is very important during the reallocation process, as it provides additional lands from the governmental land funds to bridge the lapse of unwilling participants. Land banks provide an opportunity for expansion, shaping of farmlands and creation of adjoining infrastructure; facilitates the increase in land mobility; and creates the room for a flexible land consolidation design and reallocation process [4,12,21,28,109,125,127].

-Existence of a legal framework: It determines the success of land consolidation projects by regulating the whole process from the initiation to the concluding stage. Since land consolidation projects involve the exchange and reallocation of land rights, there is a need for a strong legal basis to regulate the interferences among different private property rights by the state, for the sake of transparent protection of the rights of landowners and users, and prevention of the prevalence of any conflicts from the process. It also provides the procedures for resolution of any conflict resulting from the sensitive land valuation and reallocation processes, and regulates the modalities of participation in the projects $[4,12,28,106]$. According to Bullard [99], the legislation is not only meant to address land fragmentation, but also to prevent its reoccurrence in future. For this, the absence of the legal frame is considered as a major obstacle to the success of any land consolidation project.

-Level of political structure: It determines the political will of the state to support land consolidation projects, which in turn dictates the type of approach to follow, the duration of the project, its implementation procedures and success. When there is a high level of political will, the government takes a primary initiative to finance land consolidation programs at large scale, which in turn stimulates the willingness of voluntary participation of farmers and reduces the duration and costs of implementation. In contrast, the lack of political will slows down the process, and induces farmers to adopt cheap approaches on voluntary basis with no direct influence of the state [16,28].

-Existence of problematic land fragmentation: Since land consolidation is designed to solve the existing problems of land fragmentation, there is a need to know the available forms of land fragmentation in a specific local area, and their problematic circumstances to inform the suitable land consolidation and other approaches, since not all land fragmentation problems need land consolidation control strategies, neither are all fragmentation forms problematic $[4,11,20,21,30,31,33,75,130]$. The review of existing documents has revealed that the modern land consolidation is only suitable for physical (internal) fragmentation problems of big farms. Expanding the stipulations of Abubakari et al. [12] and Asiama et al. [28] for the availability of a certain type of land fragmentation as a precondition for an introduction of land consolidation projects in a given area, we argue that there should be a problematic land fragmentation suitable for land consolidation strategies since some fragmentation forms like tenure fragmentation might need different other strategies for their control. It has further been found that the adoption of non-suitable land consolidation strategies to the existing local land fragmentation problems has led to their failure in many countries like Kenya, Malawi, Japan, and others (ibid).

-Biophysical/geographical/agroecological/environmental conditions: Variations in topography (slope distribution), soil quality and water distribution, and the microclimatic conditions determine the forms of land fragmentation and which control strategies are suitable in a given area with respect to the benefits and costs associated with the valuation and reallocation activities. Contrary to hilly and mountainous topographies characterized by high diversity or heterogeneous microclimatic conditions and soil qualities, flat terrains with quite homogeneous conditions make it easy to exchange parcels with similar charac- 
teristics and values $[12,28,30]$. Furthermore, the hilly and mountainous areas with sharp variations in surface characteristics hinder the creation of regular shapes and infrastructures as land boundaries may naturally follow the physical characteristics of the terrain like hill tops or valleys [12,13,28,40,107]. King and Burton [97], Bentley [30], and Janus et al. [108] argue that due to the sharp variations in soil quality, and agroecological conditions in mountainous and hilly lands, the costs of consolidation may exceed its benefits, which dictates the development of different consolidation approaches rather than focusing on economic profitability, or keeping fragmentation in such areas. Prior to the development of any land consolidation approach, one needs to consider its anticipated effects on the environment, since previous experience has shown that large comprehensive consolidation projects have led to the loss of biodiversity. There should be measures to conserve the environment within the projects, or the development of environmental friendly approaches like simplified or voluntary or small localized land consolidation projects involving few people and activities $[16,28,131-133]$.

-Technical aspects (existence of land information system and consolidation experts): Since the consolidation of parcels involves the restructuring and rearrangement of socio-spatial land characteristics like ownership, use, size, shape, location, value and boundaries, there is a need to have a well-functioning and updated land information system (LIS) to provide such information for a successful reallocation [4]. However, it is not a prerequisite prior to the establishment of consolidation projects, since the experience has shown that this database can be created later within the project [4]. Furthermore, since the implementation procedures of land consolidation vary from country to country with specific success conditions, the creation or adoption of new specific approaches adapted to the local societal needs requires some technical capacity and infrastructure, which can be provided from experts' technical knowledge $[28,134]$. Therefore, a team of experts made of land use planners, land surveyors, estate valuation surveyors, land administrators, land managers, agricultural engineers and agronomists, lawyers, socio-economists, agroecologists and environmentalists need to be in place to assist the farmers in the preparation and execution of the suitable land consolidation projects tailored to the local needs $[12,16,28,30]$.

(b) Land Banking: It is explained as the process of transferring and acquiring the ownership of small parcels from small farmers to big farmers to enlarge their holdings through sales, and/or to the government or private investors through expropriation procedures in order to use them as land funds (land banks) for the development of infrastructure and land buffer during land consolidation projects, with an overall objective of creating more operational and viable farm units $[18,98,125,127]$. Land banks provide an opportunity for expansion and shaping of farmlands, and the creation of adjoining infrastructure $[18,125,127]$. It follows the principle of ownership exchange, and targets to eliminate the size related land fragmentation problems and reduce the number of boundaries and its related conflicts $[20,21]$. It has been implemented in Western Central European countries like Germany and the Netherlands, often integrated in large land consolidation projects, although recent studies have also found it suitable to the Eastern and Central European land fragmentation problems $[4,19,21,98,125,127]$. It can be voluntary by old farmers to young active farmers willing to enlarge their farms, or compulsory through governmental agencies for agriculture and infrastructure developments projects (ibid).

(c) Voluntary parcel exchange: It involves the exchange of distant non-contiguous parcels from the farmsteads among two or more landowners, resulting in more compact farms from adjacent parcels of each landowner with more efficient spatial layout [30,98]. The main target is to reduce the distance related costs, irregular shapes, and the number of boundaries by decreasing the number of scattered plots per farm under the circumstances of subsistence economies and scarce land. This strategy has been used with success in smaller land consolidation areas with a limited number of farmers in Germany ( $§ 103 a$ FlurbG-) and the Netherlands (through a notarial agreement) where the primary benefit is in agriculture, and can be combined with land banking activities for its effectiveness [17,21]. 
More recently, it has also been considered for areas with other land uses than agriculture, most notably to suit the preservation of nature and merging ecological areas.

(d) Restrictions of the minimum parcel size subdivision, Joint ownership and Cooperative farming: For the purpose of reducing the negative effects of small farm sizes, different countries have established the legal provisions restricting the subdivision of parcels into small non-economically viable units and partible inheritance, thereby encouraging their joint ownership by many co-owners or heirs, and their cooperative farming. In joint ownership, a big piece of land is owned by many co-owners but operated by one or few farmers, where in many cases one of the co-owners (heirs) later buys the shares of other heirs, or the co-owners lease their shares to one big farmer or cooperative (tenants) under specific use rights, restrictions and responsibilities $[30,97,135,136]$. Farmers may prefer the subdivision of the title over a piece of land in terms of shares without affecting its physical characteristics (ibid). With regard to the cooperative farming, a group of farmers jointly operate one big co-owned or leased farm together or agree to cultivate one type of crop on their small plots in a given area in order to create big and more economically operational and viable farms. In both cases, farmers retain their rights over land, whereas in the latter case, the boundaries of their parcels are kept intact, which has been found as a barrier to agriculture mechanization since it is difficult to move the machinery on small separately owned plots with many boundaries [3,97,98]. This is the case of Rwanda, where the article 30 of the law governing land forbids the subdivision of agricultural and livestock land which would result into small pieces of less than 1ha, thereby encouraging the joint ownership of such parcels and their cooperative farming through land use consolidation (LUC) program or cultivation of the same priority crop $[26,33,117]$ as explained above in Section 3 (a). However, although these strategies have been used with success in many countries (i.e., joint ownership in Taiwan) with subsistence economies and growing population under land scarcity conditions to tackle and reverse the problems of land fragmentation [136], different studies report their failure in countries like India, Nepal and Rwanda, as a result of the reluctance of farmers against them $[8,24,30,32-34,97,98,123,137,138]$. These studies decry these strategies to obstruct/deprive the full enjoyment of use rights over land for independent purposes, thereby inducing many ownership and use related conflicts viewed as a result of spatial injustices [139] leading to tenure and food insecurity in cases of compulsory participation and compliance to them. Moreover, the minimum parcel size subdivision restrictions have been criticized to lead to hidden ownership fragmentation thereby increasing farmland use fragmentation and the ownership and use related conflicts over land [32,33].

(e) Land realignment: It refers to the adjustment of land boundaries between two or more land parcels with the aim of remedy to the existing encroachment problems and or land management problems. It only implies minor changes in boundaries structure of adjacent plots thereby affecting the changes in sizes and shapes of parcels. It has been applied with success under the circumstances of internal fragmentation with contiguous parcels under the same operatorship to eliminate the problematic boundaries for the purpose of merging small plots into larger economically operational units [20,28].

Besides the above commonly known strategies to control the problematic land fragmentation, various studies have documented several other socio-economic and agronomic strategies to optimize the benefits from fragmented holdings by minimizing their defective effects on agriculture production without their elimination. These include different agriculture intensification programs (intensive use of labor and inputs in small heterogeneous farms and parcels); risks management strategies (agricultural insurance, agroecological approaches, food storage, pests control measures, credits, high yielding and resistant varieties) [11,30]; on-field harvest sales and off-farm employment [30,130]; the relocation of very distant farmsteads to close the best farms [97]; and many different case specific strategies parallel to the rational farmland fragmentation conservation under different circumstances like the cases of consolidation of one agricultural use type or crop (land use 
consolidation in Rwanda and viniculture in Europe) $[16,24,27,120]$ as explained above in previous paragraphs.

Despite the variety of these documented land fragmentation control strategies, land consolidation has been broadly and commonly used as a panacea to this quandary, regardless of its different forms and specific cases [21,33]. Although both land consolidation and land fragmentation are theoretically considered as land management instruments, the dominant discourse in the literature and practice presents a common weakness of tending to show the traditional land consolidation as the appropriate tool and solution to land fragmentation problems thereby ignoring the possible benefits of the later $[30,33]$. However, some studies revealed that land consolidation alone does not solve all land fragmentation problems. Whereas it is suitable to address land fragmentation problems of Western European and Scandinavian countries in areas characterized by big farms with many irregularly shaped and spatially dispersed parcels (internal fragmentation), it does not suit the Central and Eastern European countries which have many small farms (small size problems as an indicator of tenure fragmentation), and failed to be adapted to some African and Asian countries with complex traditional land tenure systems $[20,21,28,33,88,109]$. Furthermore, empirical evidence has critically proven that it tends to favor (benefit) big farmers with many scattered plots by increasing their income from agriculture at the expense of small farmers with small plots as an important pitfall, probably due to the diseconomies of scale [27,30,119,121]. In this vein, Nilsson [27] and Muyombano and Espling [121] found land use consolidation (LUC) not relevant to the fragmentation problems of small farms in Rwanda. Besides that, it has been largely criticized by many researchers for resulting in the loss of employment in case of its introduction in densely populated countries with subsistence economies thereby leading to the increase in rural urban migration, the loss of agrobiodiversity, and food insecurity through monoculture [30,31,37,38,124,133,140-142]. For this, land banking, voluntary parcel exchange, land realignment, joint ownership and cooperative farming have been proposed as suitable strategies for other land fragmentation problems than internal fragmentation of big farms $[12,16,17,20,21,26,98,127]$. Apart from that, Bentley [30] and Blarel et al. [31] argue that the problems of land fragmentation should be eliminated by focusing on fighting its root causes through curbing the population growth, creation of off-farm employment, and increasing agriculture technology.

However, in spite of the large body of literature about land fragmentation control strategies, only few studies explicitly address how, when, where and why different land fragmentation forms and specific control strategies can be inter-related and mutually conducive. The hesitation to study these interlinkages are connected to the inherent complexity and country-specificity of land fragmentation problems. These studies argue that land fragmentation issues are complex and vary from country to country and case to case with strong dependency on local social, economic, political, cultural, agricultural, agroecological and environmental conditions. Hence, there is no standard objective strategy or measure to control this phenomenon, nor is there a successful transfer of specific strategies in different areas with different characteristics $[12,19-21,28,127]$. This makes it difficult to objectively compare and assess the effectiveness of these strategies [108]. The empirical evidence revealed that the failure to consider the local conditions prior to the transplantation of land consolidation programs has previously led to their failure in some African (Kenya, Malawi, Tanzania) and Asian countries dominated by customary and communal land tenure systems $[12,18,21,29]$. Therefore, there is a need to take into account specific local land fragmentation forms, their causes and impacts (problematical and beneficial) under specific conditions, and analyze the similarities and differences prior to any attempt to transfer any fragmentation control strategy among different areas, and/or create new progressive tools and responsible approaches suitable (adapted and updated) to the existing dynamic local conditions $[12,18,28,143]$. The idea behind is that a successful strategy in one area might not succeed in another due to the differences in operational conditions. One needs to know the factors of its success prior to its broad transplantation elsewhere. Abubakari et al. [12] in their study on land consolidation in the Ghanaian customary lands 
strongly argue that the success of any land consolidation program depends on the suitability of local conditions with its baseline conditions, with respect to land characteristics like its tenure, use, value, location, size and shape. For them, the information about the convergence or divergence of these conditions needs a careful feasibility study in specific areas under consideration. Bentley [30], Van Dijk [18], and Van Dijk [21] note that land fragmentation is minimized or reduced, when the number of owners, users or farmers (tenants) and farms in a given area (tenure fragmentation) declines, the number of irregularly shaped parcels per farm and the overall distance between them and the farmstead (physical fragmentation) drops, the number of uses/crops per farm (use fragmentation) declines, and the number of farmers who are operating/using their own lands (discrepancy between usership and ownership or tenure fragmentation) increases.

To this end, our review of the defragmentation strategies shows that land consolidation instruments are suitable to control internal (location and shape) land fragmentation of big farms through the creation of compact farms with one or few close regularly shaped big parcels, and tenure fragmentation (ownership and usership) through the creation of compact farming structure in a given region by reducing the number of owners and increasing farm sizes with regular shapes). Voluntary parcel exchange suits for internal fragmentation of small farms through the reduction of distances between parcels and homestead. Land banking is suitable for size or tenure fragmentation to reduce the number of farms/owners and increase the farm sizes in a given area, while cooperative farming is suitable for internal fragmentation in case of boundaries and shapes realignment through the joint ownership, and tenure fragmentation in case of consolidation of one use type or crop as it happens in land use consolidation in Rwanda and viniculture in Europe. The risks management strategies (insurance, resistant varieties, etc) and on field sales can be used to minimize internal fragmentation. agriculture intensification programs (inputs and labor use intensity) and off-farm employment can be suitable for reduction of land tenure fragmentation problems, while agricultural land protection policies can be suitable to prevent and reduce land tenure and size fragmentation problems. Finally, the restrictions about partible inheritance, minimum size of parcel subdivision and absentee landowners, the prevention of transfer to non-farmers and leasing suit for dealing with land tenure fragmentation, whilst the imposition of a maximum limit on the holding size suits for preventing internal physical fragmentation $[4,16,18-20,30,98,120,127,144,145]$. These strategies can be categorized into two groups of preventive (legal provisions and protection policies for agricultural land) to spot the root causes of fragmentation), and mitigation (land management approaches, socio-economic and agronomic measures) to manage the impacts of an already occurred fragmentation.

Recognizing both the potential benefits and problematic situations of land fragmentation, Bentley [30] and Asiama et al. [17] suggested a specific model of land consolidation in blocks or localized land consolidation where only spatially dispersed parcels within the same microzone with homogenous soil and agroecological conditions are consolidated. This helps to conserve and give farmers access to all types of parcels in different sites with diverse microclimates and growing conditions, for both increasing the agricultural production efficiency as well as crops diversification for risks and labor management and food security purposes through food sovereignty at the local level. In this case, land consolidation does not necessarily result in a single parcel, rather in few parcels located in different sites to keep the topographical advantages of fragmentation. Likewise, Cholo et al. [41] proposed a consolidation of small parcels into larger heterogeneous plot clusters to enhance food security by exploiting synergies between agroecological adaptation practices and land fragmentation. Adversely, Ntihinyurwa et al. [33] proposed a consolidation approach which provides farmers with single contiguous farmlands or parcels that can be cultivated with multiple crops to answer the desire to meet food diversification, risks management, labor bottlenecks management as land fragmentation claims, and agriculture production efficiency by minimizing the time and travel costs as land consolidation claims. For this, there is a need for a strong objective land capability and suitability classification prior to the 
development of any local specific land consolidation approach. Figure 2 summarizes our findings on various documented instruments, strategies and policies to control different problematic land fragmentation scenarios.

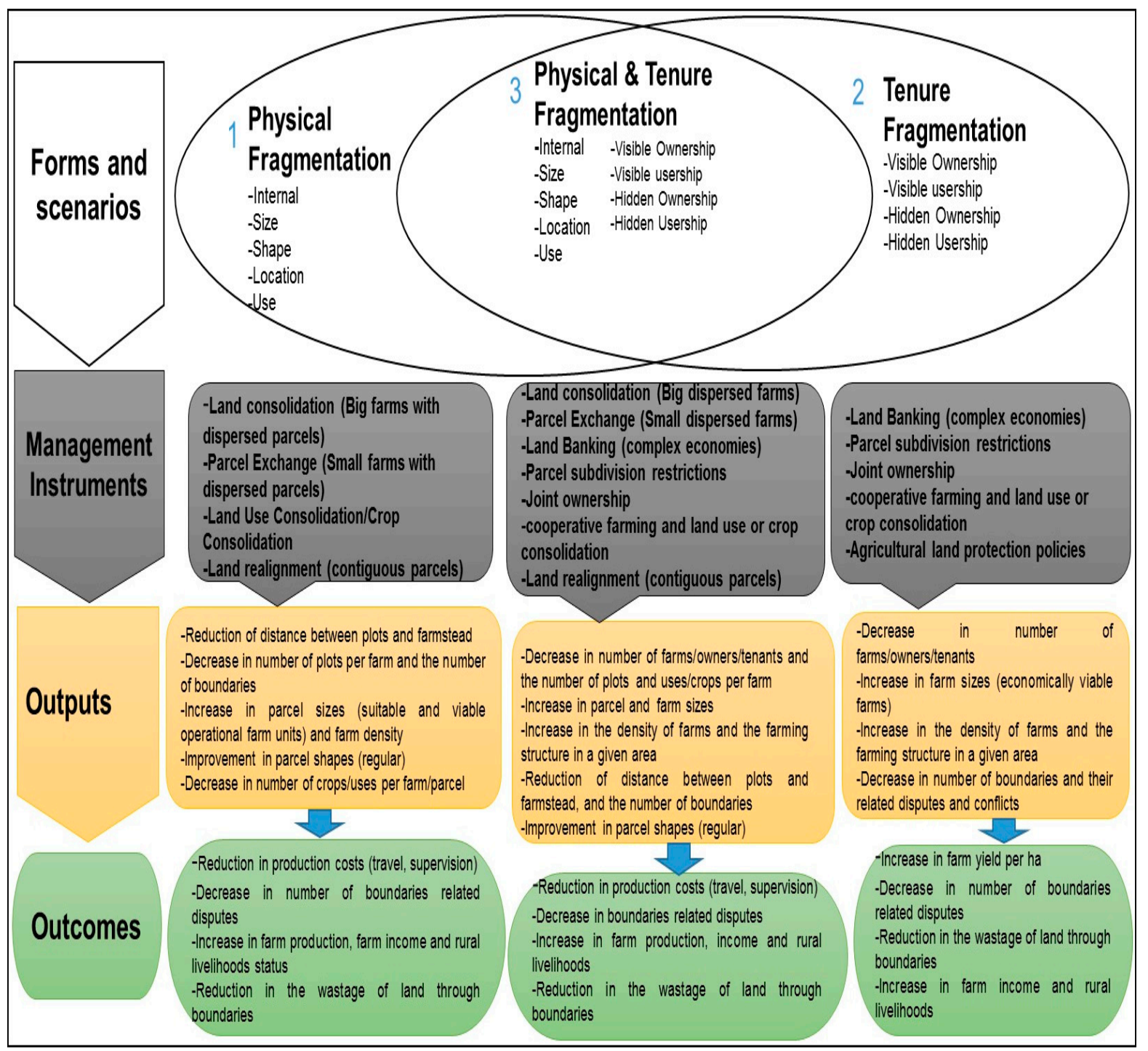

Figure 2. Synthesis of the problematic land fragmentation control strategies (instruments). Source: Developed from the reviewed literature

In summary, both the problematic and beneficial or rational land fragmentation scenarios need a certain level of management in order to optimize the income from agriculture. However, the complexity of this phenomenon makes it difficult to choose the suitable instruments (strategies) for specific circumstances, which calls for trade-offs among different alternatives and their right combinations under various local conditions. For this, the analyzed literature has on one hand revealed that the problems related to physical land fragmentation (internal, location or distance, shape, use, plot or parcel size and boundaries) can be minimized by land consolidation for large heterogeneous farms (under complex strong economies), voluntary parcel exchange and on-field harvest sales for small heterogeneous farms (under moderate and subsistence economies), land realignment for homogenous farms (contiguous plots) to eliminate and reorganize boundaries, and land use consolidation or crop consolidation for multiple uses on small plots and farms. Land tenure fragmentation problems (ownership, usership, small farm sizes, and boundaries) are reduced by land banking for small farms under complex strong economies, parcel 
sizes subdivision and absentee owners' restrictions, joint ownership, cooperative farming, land use (crop) consolidation, and agricultural land protection policies for small farms under moderate and subsistence economies. Furthermore, the introduction of insurance systems and mechanization in agriculture, and the market perfection (for food and labor) have been used as strategies to eliminate the fundamental reasons for internal fragmentation in complex strong economies with market-oriented agriculture (use of multiple zones for production diversification, risks and labor management strategies). On the other hand, different agriculture intensification programs such as the combined use of soil mineral and organic fertilizers and amendments, pests control measures, labor use efficiency and intensity, and high yielding and resistant crop varieties have been documented as suitable strategies to maximize the income from agriculture on fragmented plots under the beneficial or rational fragmentation, subsistence and moderate economic conditions (market imperfections) for risks management, labor schedule, production diversification and control of ownership and use related conflicts over land. In some special cases like mountainous areas, the costs of alleviating land fragmentation may far exceed its benefits $[11,30]$. In such cases, keeping fragmentation is more beneficial than its alleviation (ibid). Therefore, Bentley [30], Van Dijk [18], Van Dijk [21], Asiama et al. [28], Asiama et al. [17], and Ntihinyurwa and de Vries [11] suggest that any attempt to control land fragmentation should consider different local and case specific social, cultural, economic, political, environmental, and agroecological conditions of an area, and the benefit-cost analysis to guide the decisions about the suitable strategies for the sake of their success. In this regard, there is a need to develop strategies which simultaneously minimize the defective effects of fragmentation thereby optimizing or without jeopardizing its potential benefits $[33,75]$ for food security purposes. Local agroecological approaches tailored to the needs of local peasants (farmers) should be given a key place in the management of local farmland fragmentation scenarios of subsistence communities for sustainable agriculture production, farm resilience, self-sufficiency in culturally acceptable (desirable) food production, increase in food sovereignty and the household food security motives. The next section discusses this food security concept.

\section{Food Security as a Multidimensional, Multilevel and Multisource Concept}

The concept of food security has been variously defined over time across different disciplines for particular interests and goals at different spatial levels and social scales. Chigbu et al. [32] and Dam Lam et al. [146] found that by the end of 2015, there were more than 200 different definitions of food security. However, despite the subjective and sometimes contradictory conceptualizations of the term, most of these definitions are oriented towards the supply of sufficient (enough) food availability (quantity of calories) at all times (stability) to meet the needs (demands) of the growing population from domestic and wild production, stocks, food imports or purchase from the markets, and food aids [32,54,147-151]. The majority of them were following the 1789 Malthusian food availability theory, stipulating the balance between the population growth and food availability (food growth rate should not be below the population growth rate) at the macro and meso spatial levels (community, regional, national, global). This tendency persisted till the introduction of Sen's theory of food entitlement in 1981 stipulating the notions of access, affordability, allocation (distribution) and utilization of food at the micro spatial levels (household and individual) $[54,64,65,68,150]$. With an attempt to reconcile different conceptualizations of this term, FAO [69] from the World Food Summit (WFS) in November 1996 developed a more comprehensive widely accepted definition of food security as a status/situation: "when all people, at all times, have physical, social and economic access to sufficient, safe and nutritious food which meets their dietary needs and food preferences for an active and healthy life", and vice-versa for food insecurity. The same definition was extended later in 2009 in the world summit on food security, where the four pillars (dimensions) of food availability, food accessibility, food usage (utilization) and food stability (sustainability) through which food security can be measured at both national, regional, community, house- 
hold and individual levels were linked to this concept, while the nutritional dimension was added to it as an integral part $[33,54,65,146-148,150-152]$. With respect to the nutritional dimension, the concept implies that food and nutrition security is achieved when adequate food (in terms of quantity, quality, safety, and socio-cultural acceptability as components of food security) is available and accessible, and satisfactorily utilized by all individuals at all times to live a healthy and happy life $[54,67,150,151]$. This stipulates the consideration of the aspects of availability, accessibility and stability of food of acceptable quantity, quality, safety and diversity, based on the social and cultural preferences of any society or an individual at all levels [67]. Whenever one of these aspects is not met, people may suffer from hidden and visible hunger [33] and malnutrition, which negatively affect the health and livelihoods of the population. Since the aspect of availability in this definition stands for the supply of enough food of acceptable quality and quantity to broadly meet the demands of the population, it is mostly used to measure food security at the meso and macro levels (community, global and national); Whilst the accessibility and utilization entailing the capacity of individuals or households to meet their preferred food needs for an active healthy life, stand for the micro levels (household and individual). The same concept of food security highlights the chronic and the transitory food insecurity at all these levels/scales, as a result of instability of all the other aspects/pillars. The household food security is the application of this concept to the family level, where individuals within the households are the hub of concern $[33,54,65,69,148,151,153]$.

The achievement of food security at all levels following the FAO definition is function of different factors including the economic status of the household, socio-cultural norms and values, demographic characteristics, agricultural system, education level, and environmental and agroecological characteristics of the area, to cite only few $[32,33,65,69,154]$. Surprisingly, the popular logic of achieving food security has over time focused on reducing the population growth through different family planning policies, and boosting agriculture production to keep the balance between the food demands of the growing population and food availability (supply) at the macro and meso levels (national, regional and community), thereby ignoring its entitlement and sovereignty at the local (household and individual) levels $[46,47,54,65,68,149,155]$. However, since food security is a very complex, multidimensional and multilevel concept, difficult to achieve in silos, this can only be possible if other external economic, socio-cultural, political, agroecological, and environmental factors are overlooked. Food security entails more than growing enough food, since it implies the demand for it, as well as the supply, the quality as well as quantity, diversity as well as accessibility, an adequate diet (culturally acceptable quality and quantity) today and assurance of one tomorrow [11,32,33,54,65,67-69,148,150,153]. It has the aspects of quality, access/affordability, acceptability, utilization/usage and stability/sustainability which can only be achieved when everyone in the household has access to regular, safe, nutritious and enough acceptable food to meet his/her food preferences $[11,32,33,65,68,69,150]$. Therefore, in the existing critical context of the ever growing fluctuations in climate and food prices which directly affect the household's food acquisition (domestic and wild agriculture and animal production, purchase, aids, and imports) and allocation (distribution and usage), and food safety concerns, the achievement of food security at the micro levels requires the change of food production paradigms. This needs the shift from the mass food production systems through conventional agriculture and monoculture, and consumption patterns prioritizing the quantity and availability, towards more diversified and locally produced food stuffs through sustainable, climate or natural risks resilient and smart agriculture systems, following various agroecological approaches including the polyculture (growing wide diversity of food crops in space and time) $[11,32,33,37,41,45-48,71,156,157]$. This can help to sustainably meet the cultural dietary needs and food preferences of acceptable quantity, quality and safety for all local people, as the suitable method of achieving food sovereignty, an adaptation strategy to the existing climate change realities for ending hunger and malnutrition, and local approach of 
meeting food security stipulated by many policy initiatives and goals like the SDGs 1.4; $2.1,2,3,4,5 ; 12.2 ; 13$ \& 15.3,4,5,9 [11,32,37,38,41,46-48,71,141,155,157-165].

Being the main factor of food production in many countries, the agriculture production of enough staple food crops as the basic component of food systems for food security (food supply side) requires the focus on agriculture intensification of small scale farms or agroecological strategies on fragmented land, and agriculture expansion of large scale farms on consolidated land, to meet the local needs and food preferences of the growing population. Recent studies and social movements advocate for the achievement of local food security by focusing on the concept of food sovereignty, which stipulates the self-sufficiency and autonomy in food production by local small scale farmers through various agroecological methods and agricultural systems tailored to their needs, knowledge, cultural values and traditions, and other particular circumstances $[46-48,155,165]$. Nonetheless, this does not alone guarantee the complete solution to the problem of food insecurity, since other aspects like food utilization and food market entail more than that $[32,65,150]$. The evidence has shown that food insecurity may exist in cases of high availability and accessibility of food in sufficient quality and quantity, mainly due to the lack of knowledge about the right preparation and combination of balanced nutritional diets, and the basic health and hygienic services like clean water (ibid). To this end, one needs to focus on a holistic and careful assessment of food security status, by considering all its underpinning factors at all levels. Figure 3 summarizes these various factors of food security.

As Figure 3 summarizes, food security as a multidimensional and multilevel concept cannot only be achieved by a single instrument. It requires a holistic approach which considers the contributions of different factors at different levels of analysis to create food systems that offer the possibilities to meet the availability of qualitatively and quantitatively acceptable food in a given area, accessible (affordable) to all people, with the best and balanced combinations (utilization) to meet the nutritional diets/needs and food preferences of the ever growing population at the regular basis (sustainability/stability) with scarce resources or production factors (land and capital) for an active and healthier life. Considering the growing challenges of climate change and other natural shocks from food production side, an attention should be focused on the trade-offs between the role of some agroecological principles like crops diversity on food stuffs diversification as a source of qualitative, sustainable, acceptable and resilient food systems on one hand, and the quantity of agriculture production to meet the food needs and demands of the growing population irrespective of its quality on the other hand, on either fragmented or consolidated land parcels at the local levels (community, village, household and individual) [11]. The growing tendency is that poor people are choosing to compromise to food quality and quantity aspects for the benefit of food stability in case of shortages of food availability and accessibility as a result of climate change and price fluctuations realities, by creating more sustainable resilient farms through local agroecological farming systems $[46,47,156]$. The next section establishes the relationship among farmland fragmentation, farmland consolidation and food security concepts. 


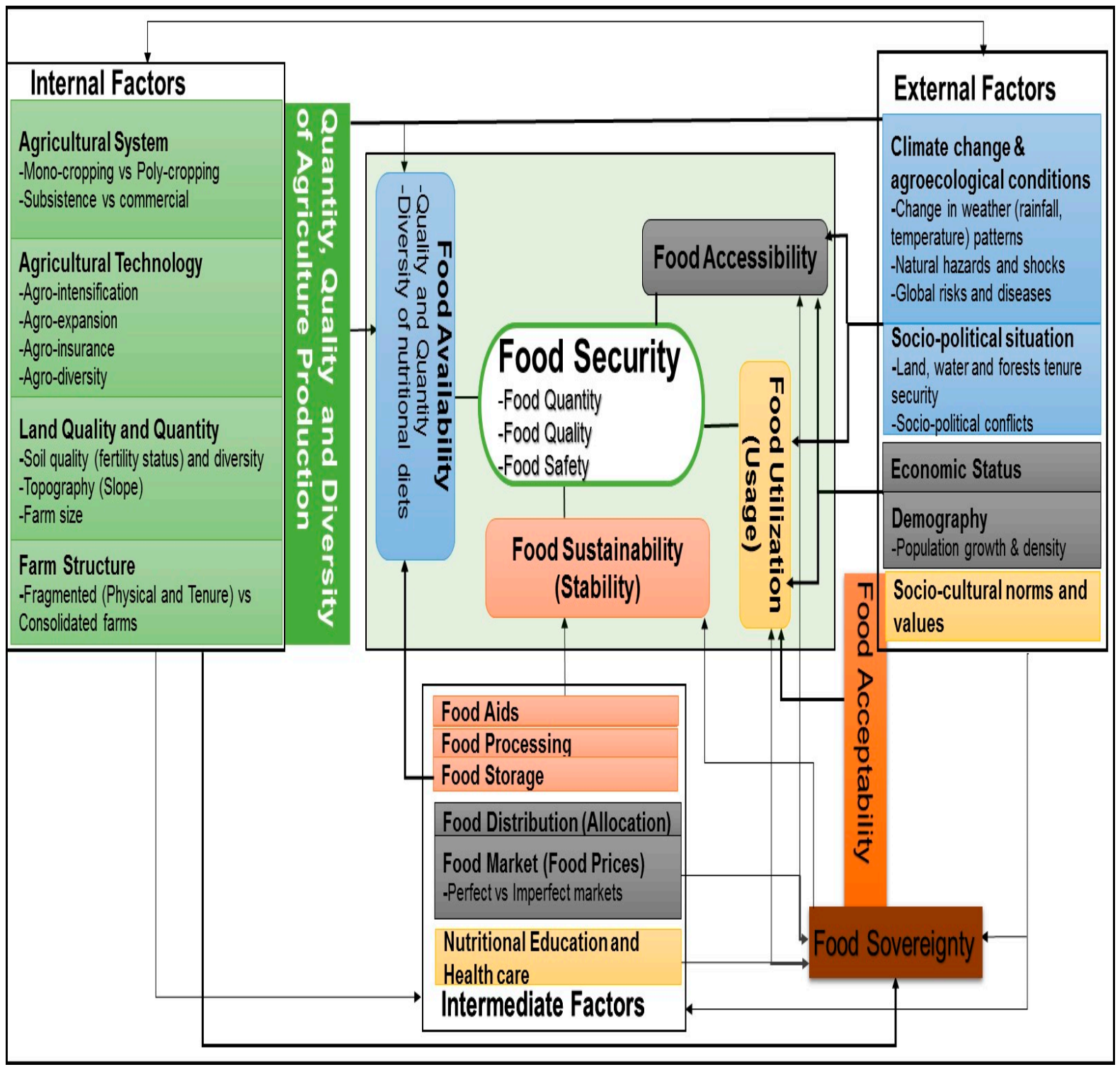

Figure 3. The multidimensionality of food security as influenced by internal and external factors. Source: Developed from the reviewed literature

5. Farmland Fragmentation, Farmland Consolidation and Food Security Nexuses: Relationships, Overlaps, Research Gaps and Future Perspectives

5.1. Relationships, Overlaps and Research Gaps

Farmland fragmentation and farmland consolidation are two interlinked concepts theoretically considered as instruments of agricultural land management for food security purposes $[11,33,51]$. In this vein, regardless of the fragmentation or consolidation statuses and scenarions, the farmland remains a fundamental asset for food security [33]. However, while there is enough empirical evidence and substantial literature about the relationship amid land fragmentation, land consolidation, land productivity, agricultural production, and farm profitability and efficiency, only few disaggregated studies address the linkages between farmland fragmentation, farmland consolidation and food security. Furthermore, from our critical review, there is a lack of comprehensive studies that have documented the linkages between the two concepts and food security as a multidimensional, multilevel, and multisource concept. Therefore, this section builds on the existing disaggregated studies about these three concepts and adopts the conceptual reasoning approach which 
follows the rationalist theory to fill this litterature and knowledge gap through the analysis of different related theoretical connotations.

Foremost, a large category of studies shows the physical land fragmentation (internal, location, shape, use) as a defective phenomenon, and a major threat to agriculture production, farm productivity and profitability, by hampering farm efficiency and the economies of scale, thereby positing land consolidation approaches as a panacea to this problem $[2,3,6-8,10,12,14,29,52,66,89,90,105,107,118,166-174]$. These studies broadly argue that farming on small scattered and irregularly shaped plots increases the travel and supervision costs due to long distances between parcels and the household, which reduces the yield per hectare, farm profitability, and abandonment of farming activities on very distant parcels in some cases. Furthermore, regardless of the distance and adjacency of parcels, land tenure fragmentation leads to small farms with small non-economically viable land units, which in turn hinders the economies of scale, since the mechanization and expansion of market-oriented agriculture is not tenable on such units [4]. This reduces the quantity of agricultural production and food availability or supply in a given area as a pillar of food security. Therefore, the majority of these studies propose land consolidation as the appropriate solution to these issues. They back this position by showing how consolidated and compact big farms with larger farm units and parcels or plots decrease the agriculture production costs and increase the yields per hectare and farm profits as the key characteristics of the economies of scale, which in consequence positively impacts on the supply (availability) and sustainability of enough quantity of food to meet the food demands of the population for food security in a given area. For Lerman and Cimpoieş [118], big consolidated farms offer higher agriculture production and econimic performance than small fragmented ones, which incresases the food security status and the well-being of the rural population. From the proponents of this view, the quantity of agriculture production of food crops matters most, in order to satisfy the food demands of the growing population following the Malthusian theory of population growth and food availability or supply of 1798 [54] and fill the gap stipulated by the reverse relationship between the population growth and the limited food productive capacity of land resources in this theory. Likewise, this claim is shared by the advocates of other alternative strategies like land banking, cooperative farming, and joint ownership against the tenure or size fragmentation of farmland. They tend to believe that food security of the growing population can be met by producing enough quantity of food crops through agriculture mechanization and the economies of scale, which can only be achieved on consolidated or big farms $[21,106,109,125,127,136,175]$.

Nevertheless, different studies have criticized some farmland consolidation approaches to lead to the establishment of monoculture systems which result in production of single or few types of food stuffs, thereby negatively affecting food diversity and balanced nutritional diets and inducing food insecurity $[30,31,37,38,176,177]$. This is the case of Land Use Consolidation program in Rwanda, criticised of worsening food insecurity issues by promoting the monoculture system at the expense of multicultural one and its irreplaceable adaptive benefits, through the reduction of agriculture production diversification as a source of food diversity aspect at the household level, despite its major outcomes in terms of boosting the national production of 8 priority crops grown in this program $[24,27,32-34,119,121-123,137,178]$. These studies posit that the availability of enough quantity of food of some priority crops at the national level through LUC does not necessarily mean that the needs and food preferences of households members are met, while the practical evidence has revealed the increase in households vulnerability to food insecurity since the introduction of this program in 2008 (ibid). Combined with the consequences of climate change (droughts and floods from changes in rainfall patterns) and imperfect food market, this LUC program has been pointed out to worsen the problem of food insecurity at the household and individual levels, by reducing its quality, accessibility, acceptability, and sustainability aspects in some parts of the country [32,33]. 
Despite these findings, the debates over what to do with farmland fragmentation, farmland consolidation and food security have often been disassociated from those related to climate change and agroecology, and only linked with agriculture production, due to the presumed negative impacts of farmland fragmentation by policy makers. Following the multidimensional nature of food security, the prevalent justification for land consolidation is that it increases the farm size and reduces the producion costs associated with the distance, and thus contributes to food security given higher quantities in food production from food crops. Nonetheless, this logic makes sense when food security is viewed from the lens of quantity, since food security is much more than the quantity of food. It includes the aspects of diversity, quality, access, sustainability, acceptability and utilization of food $[64,65,69]$ along with food sovereignty $[46,47,155]$, which are also achievable under the conditions of land fragmentation scenarios $[11,32,33,66]$.

Therefore, a different category of studies witnesses the evidence of positive relationships between physical farmland fragmentation and food security. These studies argue that physical farmland fragmentation contributes to the improvement of the aspects of food quality through the diversity of nutritional diets, and the regular (sustainable) availability and accessibility of food at the household and individual levels under the conditions of subsistence economy, climate and food prices fluctuations, and vice versa for farmland consolidation $[11,30-34,37,38,41,42,50,57,94,122,141,157,176,177,179,180]$. These advocates of this standpoint commonly argue that farming on spatially and topographically fragmented and dispersed parcels with irregular shapes offers farmers the possibilities to grow a wide range of diverse crops in areas with different crops suitabilities and growing conditions for the purposes of food stuffs diversity production, farm resiliency, and the management of risks of climate change and food prices fluctuations. This in turn increases food diversity, quality, accessibility, acceptabiliy, and sustainability of subsistence households, thereby inducing the likelihood of meeting food sovereignty and food security at the local levels [11,46], following the economies of scope, resilience, agroecology, and complexity theories. In the same vein, Blarel et al. [31], Alexandri et al. [179], Ciaian et al. [37], Cholo et al. [41], Knippenberg et al. [45], Ntihinyurwa et al. [33], and Ntihinyurwa and de Vries [11] advance that farmland fragmentation leads to the cultivation of diversified food crops and the production of a diversity of food basket for self-sufficiency of subsistence farmers in order to meet their nutritional demands and food security at cheap prices, as the cheapest strategy to achieve the household food security under the circumstances of climate change, land scarcity and food market imperfections. This claim coincides with the advocates of agroecology and food sovereignty, which posit the achievement of food security at the local levels through self-sufficiency and autonomy in food production tailored to the needs of cultural and traditional diets of local subsistence farmers using various local agroecological methods (temporal and spatial crops diversification through polycultures, and the knowledge of local peasants) on more resilient small scale farms [46-48,70,155,165]. The collective of these studies stipulates that, the more the differences and high diversity or heterogeneity in land and soil qualities; the higher the variety of soil-crop suitability classes and production potentials; the higher the crops diversification (agrodiversity), farm resiliency and food stuffs diversity; the higher the self-sufficiency in food production, the higher the nutritional balance; the higher the food quality and sustainability; the higher the food acceptability and sovereignty; the higher the food security [33]. Furthermore, contrary to the principles of the economies of scale theory, the proponents of this view counter argue that land tenure or size fragmentation (small farm sizes) backs the diseconomies of scale theory stipulating the inverse farm size and agriculture production relationships, following the Boserup's theory of population growth and agriculture intensification of 1965, probably due to imperfections in labor market in subsistence economies, and the growth of technology in agriculture $[31,49,50,63,181,182]$. This implies that the intensification of agriculture leads to better outputs in terms of agricultural production on small farms than on bigger ones, which directly impacts on food availability (quantity and quality). TWN and SOCLA [155] argue that small farms are more productive than large farms, 
if the total output is considered rather than yields from a single crop. Nevertheless, this Boserup's theory stipulating the proportional relationship between the population growth and agriculture intensification $[11,63]$ has shown its limitation at a certain critical threshold of very high population density, thereby giving a reason to the Malthusian theory in such circumstances $[55,56]$.

However, in case the consolidation practices offer to farmers the options of growing multiple crops on consolidated plots (voluntary land consolidation models), and the provision of agricultural insurance services and resistant crop varieties, there are no more reasons for keeping fragmentation. Such consolidated parcels lead to high agriculture production of diverse crops, which in turn results in the regular and adequate availability and accessibility of food of acceptable quality and quantity, thereby contributing to the improvements in household food security $[4,16,30,111,157]$. Moreover, comprehensive land consolidation models may integrate some specific programs of food processing, food storage and nutritional education to contribute to the improvement in food quality through more balanced nutritional diets and food accessibility and stability aspects as a support to food availability, to meet the household food security in its multidimensional conceptualization $[4,16]$.

Besides the effects of farmland fragmentation and consolidation strategies on food security, the status of the latter may also determine the kind of decision about the fragmentation management approaches. Since the primary objective of consolidation approaches is to increase the food security status by sustaining food availability (supply) to meet the food demands of the growing population through agriculture production, these approaches may not be necessary in case of the lack of food insecurity problems in a given area (when food security already exist under fragmentation scenarios of big farms) $[4,18,21,30,31,37,38,41,50]$. This is the case of countries with abundant land and low population densities like the USA, Russia, Canada and many others.

Finally, the critical review has drawn the reciprocal relationship between farmland fragmentation and farmland consolidation concepts. Farmland fragmentation is documented as a precondition and milestone for an establishment of any farmland consolidation program in a given area $[4,12,18,19,98]$, and exists in an area which was previously consolidated according to the Gestalt theory of a whole [53]. Notwithstanding their reverse theoretical meanings, the two concepts share the same practical measurement indicators (see Ntihinyurwa and de Vries [75] for more details). Figure 4 summarizes the theoretical relationships between farmland fragmentation, farmland consolidation and food security. These relational linkages in literature lay a foundation for a theoretical model which could be adapted or used by scholars for building frameworks on the subject (Figure 4).

Simply put, Figure 4 shows that any farmland fragmentation and consolidation scenario which engages the multi-cropping system (agroecological approach) and agricultural intensification, food processing and storage, and nutritional education programs may lead to the achievement of food security at the household level, except in cases of lack of those intensification programs on small non-resilient farms. On the other hand, the consolidation programs implying the mono-cropping systems are susceptible to lead to food insecurity status through malnutrition (under and / or over nutrition), especially when combined with external factors like market imperfections, climate change, natural shocks, and the absence of the above-mentioned supporting programs. In this respect, the concepts of farmland fragmentation, farmland consolidation and food security are interlinked. The type of this interlinkage is determined by external factors like climate change, socio-economic status, agrobiodiversity (agroecology), demographic aspects, and land characteristics. Therefore, for the purpose of achieving the sustainable development goals (SDGs 1,2,12,13 and 15) stipulating the attainment of the multidimensional food security through sustainable (climate resilient) land management strategies (see Paragraph 6 of Section 1 for specific targets), any attempt to achieve food security through agricultural production should consider the importance of all the above-mentioned factors at the local levels for its success. 


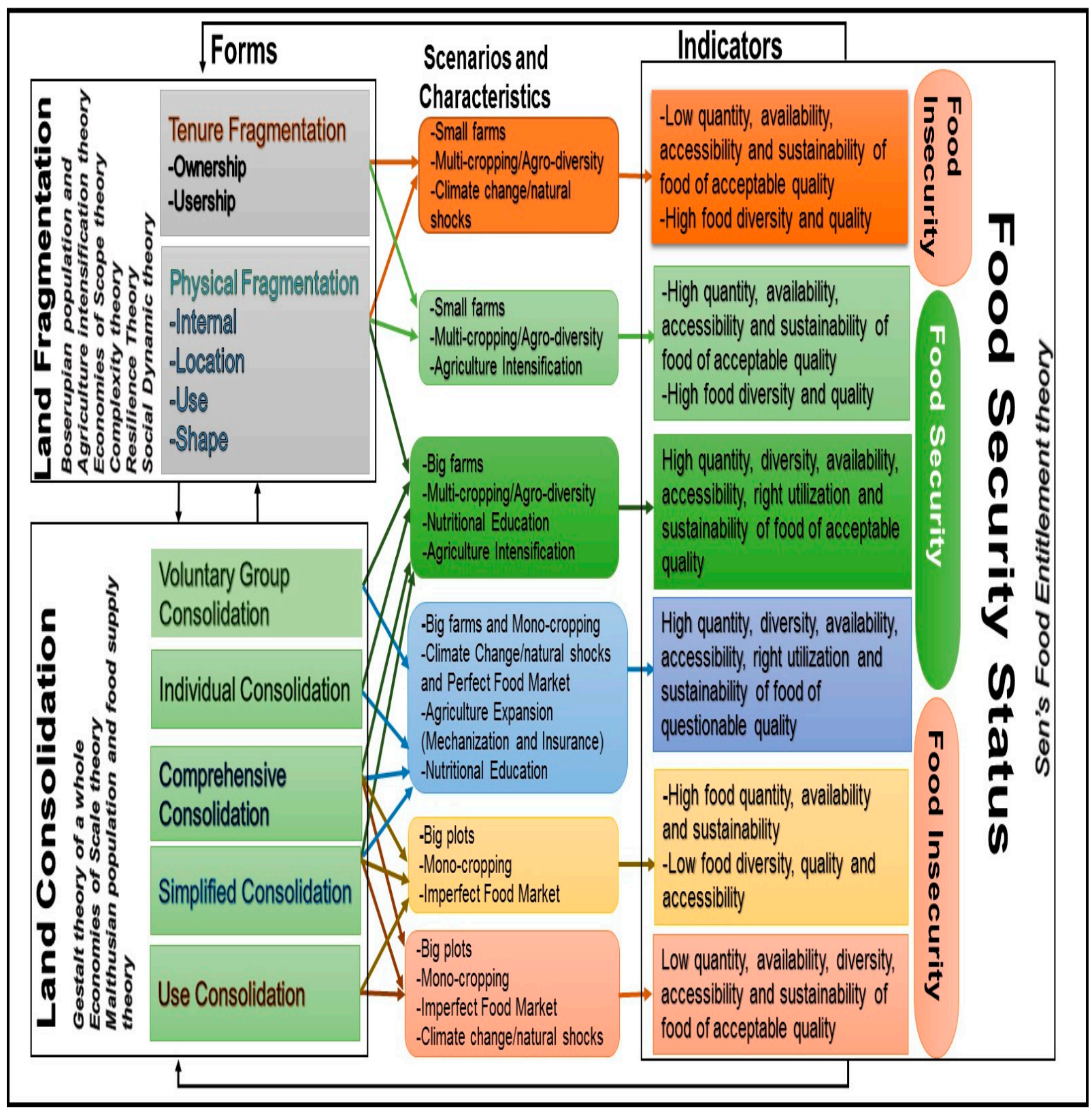

Figure 4. Theoretical relationships between farmland fragmentation, farmland consolidation and food security. Source: Developed from the reviewed literature

\subsection{Reconceptualization of Farmland Fragmentation Management for Food Security}

Recognizing the complexity, polarity and multidimensional nature of farmland fragmentation and food security concepts, there is a need to develop the local context specific and progressive farmland fragmentation management strategies, which consider both its defective and beneficial sides following the dynamic systems theory [84-86] and agroecological approaches (elements, principles, and methods) $[47,48,155,165]$, rather than focusing on the blind subjective and irrelevant decisions of either defragmentation through different consolidation programs for food quantity and availability, or fragmentation conservation for food quality, accessibility, sustainability, acceptability and sovereignty purposes. Since our critical review of the literature has shown that both the defective and beneficial fragmentation forms may coexist in the same area, the identification of those forms, their causes and impacts, and assessment of the local social, cultural, economic, political, biophysical, agroecological and environmental conditions in a given area along with the benefits-costs 
analysis prior to any decision, would give an insight on the suitable combinations of strategies. This would further serve as an important guidance to policy makers and research scholars, and the best approach for the optimum management of this phenomenon. This position is theoretically and empirically supported by previous studies of Bentley [30], Van Dijk [18], Van Dijk [21], Asiama et al. [28], Asiama et al. [17], Ntihinyurwa and de Vries [11], and Ntihinyurwa and de Vries [75] in Sub-Saharan Africa and Europe. Being progressive, flexible and fit for specific situations and scenarios, this approach can accommodate different emerging solutions to new problematical situations, under the dynamic climate change realities and changes in local conditions in a given area. Building from this approach, we propose the following conceptual model for farmland fragmentation management in Figure 5 to refresh the existing sporadic and outdated conceptualizations about the management of this phenomenon, considering the major global threats of climate change, natural shocks, population growth, and urbanization. The model implicitly shows when, where, how and why one could opt for defragmentation or fragmentation conservation, through the hypothetical relationship between various farmland fragmentation scenarios [11,75], the proposed suitable management strategies or solutions, and food security and the general livelihoods of the rural (local) farming population. It results from a combination of variance and process models through abstract modelling techniques and the deductive logic conceptual reasoning approach [72-74,77,87]. After being empirically tested in different local areas, the outcomes from this model will be translated into suggestions for farmland fragmentation management strategic options under different specific local conditions.

For the sake of optimizing the income from agriculture and meeting food security, both the problematic and rational farmland fragmentation scenarios need a certain level of management. In this regard, as Figure 5 shows, the problems related to Physical Farmland Fragmentation (internal, location or distance, shape, use, small parcel and plot sizes, and boundaries) can be minimized by farmland consolidation in case of large heterogeneous farms (under complex strong or market-oriented economies); voluntary parcel exchange and on-field harvest sales in case of small heterogeneous and homogenous farms (under moderate and subsistence economies); land realignment in case of homogenous farms (contiguous plots) to eliminate and reorganize the boundaries; and farmland use consolidation or crop consolidation in case of multiple agricultural uses on small plots and farms. On the other hand, Farmland Tenure Fragmentation problems (ownership, usership, small farm sizes, and boundaries) can be reduced by land banking and off-farm employment in case of small farms under complex strong or market-oriented economies; restrictions about the parcel sizes subdivision and absentee owners, joint ownership, cooperative farming, farmland use (crop) consolidation, and agricultural land protection policies in case of small farms under moderate and subsistence economies. Furthermore, to prevent the worsening of the tenure fragmentation situation, where possible, the combination of these strategies with strong family planning measures that curb the population growth following the Malthusian theory of population and food supply, could generate good results [54-56]. 


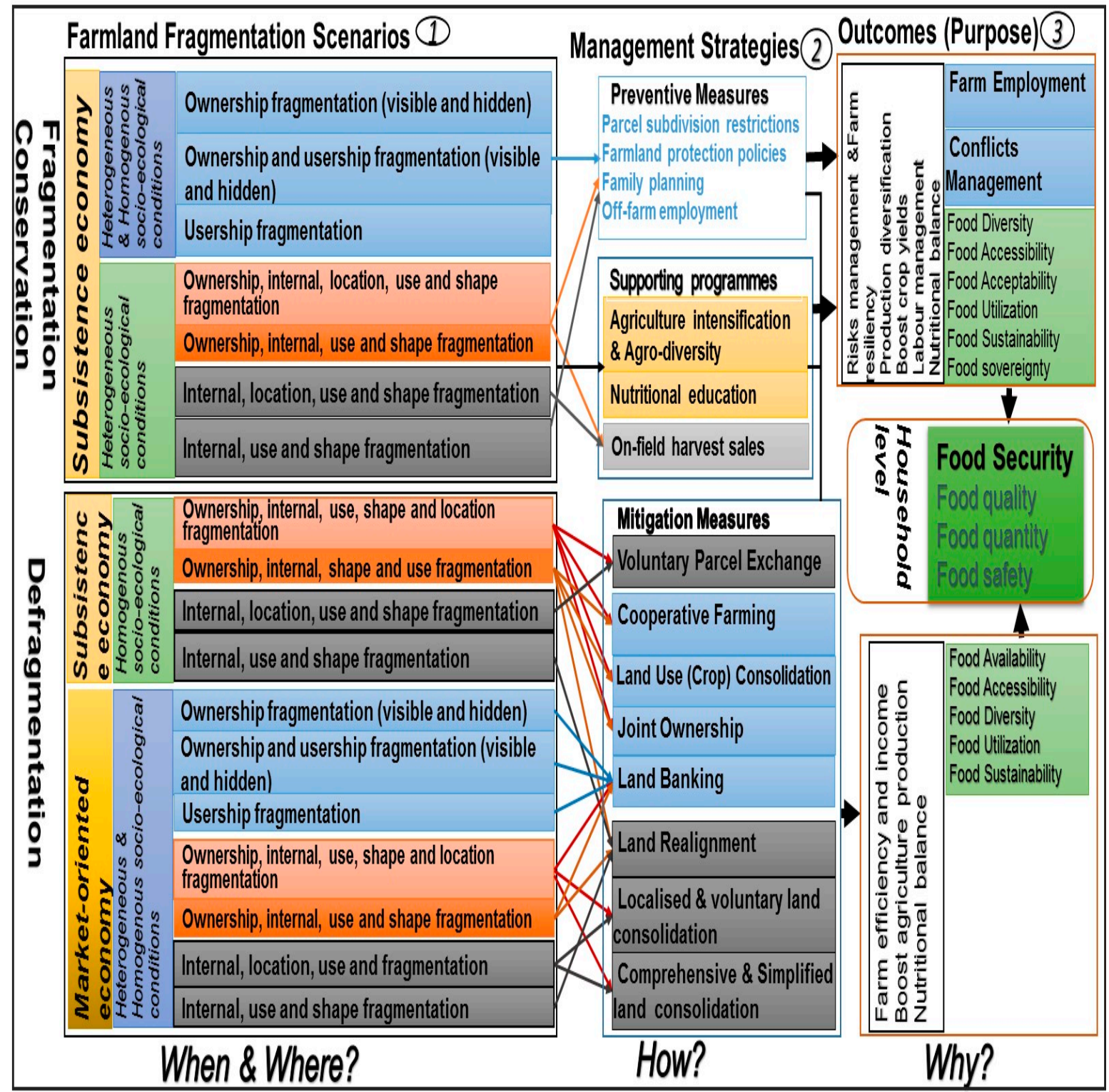

Figure 5. Farmland Fragmentation Management Conceptual Model. Source: Developed from the reviewed literature and the logic conceptual reasoning and modelling [11,73-75,77,81,87].

Considering the coexistence of both rational and defective fragmentation in the same area, there is a need to develop strategies that simultaneously minimize the negative effects of fragmentation thereby optimizing or without jeopardizing its potential benefits. To this end, the following specific consolidation models suggested by different researchers would apply in different specific cases after a careful benefits-costs analysis:

* Land consolidation in blocks or localized land consolidation: This model is suggested by

Bentley [30] and Asiama et al. [17] in areas where only spatially dispersed parcels within the same micro-zone characterized by homogenous soil and ecological conditions are consolidated. This helps to conserve and give farmers access to all types of parcels in different sites with diverse microclimates and growing conditions, for both increase in agricultural production efficiency as well as crops diversification for risks and labor management, and food security purposes. In this case, land consolidation does not necessarily result in a single big parcel, rather in few big and medium size parcels located in different sites to keep the topographical advantages of fragmentation. This would apply to cases of physical (internal) fragmentation under subsistence 
and developing (middle-income) economies characterized by high heterogeneity of agroecological conditions. This fits with the consolidation model of small topographically dispersed parcels into larger heterogeneous plot clusters proposed by Cholo et al. [41] to enhance food security through the exploitation of synergies between adaptation practices and farmland fragmentation in Ethiopia. The voluntary group, simplified and individual land consolidation models, and voluntary parcel exchange strategies would also apply to this case.

* Multicropping-based land consolidation approach: Suggested by Bentley [30] and Ntihinyurwa et al. [33], this model provides farmers with single contiguous farmland parcels which can be cultivated with multiple crops to answer the desire for food diversification, production risks and labor bottlenecks management as farmland fragmentation claims on one hand, and agriculture production efficiency by minimizing the time and travel costs as farmland consolidation claims on the other hand. This applies to the cases of small parcels spatially scattered in the same topography with quite homogenous agroecological conditions, in both subsistence and strong economies for both food quantity and diversity (quality) purposes. The comprehensive, simplified and voluntary land consolidation models, along with land banking programs would also fit for this case, if farmers fully enjoy the use rights over their lands.

The success of these specific models requires a strong objective land capability and suitability classification prior to their development, based on a functional soil information system (SIS), which lacks in many developing and underdeveloped countries. Moreover, drawing from the study of Chigbu et al. [32] on tenure and food security responsive land use consolidation in Rwanda, the consolidation of land for agriculture expansion through market-oriented and monoculture based systems in more homogenous areas with less variability in agro-ecological, physical (soil, slope, water, etc), socio-economic, cultural, and climatic conditions for food quantity and availability; and the conservation of multiculture based systems on either consolidated or fragmented land in more heterogeneous conditions through various agroecological approaches as a risk management strategy, climate change resilience and adaptation strategy, and food crops diversification for food diversity and quality, accessibility and sustainability, cultural acceptability and sovereignty, could offer optimal solutions to farmland fragmentation and food insecurity problems.

In developed countries characterized by complex strong economies with marketoriented agriculture and perfect food, land and labor market, the fundamental reasons for internal fragmentation conservation (use of multiple zones for production diversification, production risks management, and labor management strategies) are always removed and compensated by the introduction of insurance systems and mechanization programs in agriculture $[18,30,98]$. In this case, keeping fragmentation would be useless. In contrast, different agriculture intensification and agroecological programs including the combined use of soil mineral and organic fertilizers and amendments, pests control measures, labor use efficiency and intensity, crops diversity, and high yielding and resistant crop varieties could be the most suitable strategies to maximize the income from agriculture on fragmented plots under the circumstances of beneficial fragmentation in subsistence and moderate economies characterized by high population densities and market imperfections. This can offer the benefits of risks management, labor schedule, agriculture production diversification, and control of land ownership and use related conflicts, thereby by increasing food sovereignty and the local (household and individual) food security, following the Boserup's theory of 1965 on population growth and agriculture intensification [63] below a certain critical threshold. This has empirically been evidenced by various studies in different countries [30,31,33,37,41,50,55,56,94,155]. Furthermore, in some particular cases like mountainous areas under subsistence economies where the costs of alleviating farmland fragmentation outweigh its benefits, keeping fragmentation would be more beneficial than its alleviation $[11,30]$. 


\section{Conclusions}

In the context of contrasting advocacies for farmland fragmentation, farmland consolidation, farmland use consolidation and food security nexuses, this study extends the discourse by explicitly and comprehensively displaying different conditions under which and how one could choose between farmland fragmentation conservation and defragmentation (consolidation) policies or both, as responsible farmland management tools to achieve food security. With logical reasoning, the study critically analyzed different documented farmland fragmentation scenarios, their problematical (defective) and rational (beneficial) situations under different circumstances, and proposed their suitable specific management models to achieve the multidimensional food security at the micro levels (household and individual) as a new contribution to the knowledge in the field of farmland management.

In contrast to the dominant standpoint of the current literature, this study reveals that both farmland fragmentation and farmland consolidation impact on food security in different ways at different levels. Therefore, for the purposes of achieving food availability, accessibility and sustainability for food security at all levels, the defragmentation process to minimize the problems related to physical farmland fragmentation (internal, location or distance, shape, use, small plot sizes and boundaries) can take the form of farmland consolidation for large heterogeneous farms under complex strong or market-oriented economies with high land availability; voluntary parcel exchange and on-field harvest sales for small heterogeneous farms under moderate and subsistence economies with land scarcity; land realignment for homogenous farms with contiguous plots to eliminate and reorganize the boundaries; and farmland use consolidation or crop consolidation for multiple uses on small plots and farms. Similarly, farmland tenure fragmentation problems (ownership and usership, small farm sizes and boundaries) can be prevented and minimized by land banking for small farms under complex strong economies; restrictions about the parcel sizes subdivision and absentee owners, joint ownership, cooperative farming, farmland use (crop) consolidation, agricultural land protection policies, and family planning measures (to curb the population growth) in the case of small farms under moderate and subsistence economies. This hypothetical stance is backed by the Malthusian theory of population and food supply, economies of scale and Gestalt theories, which commonly advocate in favor of agriculture expansion on bigger consolidated farms than on fragmented ones. On the other hand, for the purposes of food diversity, quality, accessibility, independency, acceptability, sovereignty, and sustainability for food security, different agriculture intensification and agroecological programs, and other land saving technologies could be the most suitable strategies to maximize the income from agriculture on fragmented plots under the circumstances of beneficial fragmentation in subsistence and moderate economies characterized by high population densities, market imperfections and land scarcity. These include the combined use of soil mineral and organic fertilizers and amendments, crops diversification, pests control measures, labor use efficiency and intensity, and resistant and high yielding crop varieties. This position is supported by the Boserup's theory on population growth and agriculture intensification below a certain critical threshold. In case of the coexistence of both rational and defective fragmentation scenarios in an area, various specific strategies which could simultaneously minimize the defective effects of fragmentation thereby optimizing or without jeopardizing its potential benefits can give better and more balanced or optimal solutions. These include land consolidation in blocks or localized land consolidation models for internally fragmented subsistence farms with plots spatially scattered in different heterogeneous topographies, and multicropping-based land consolidation approaches for fragmented farms with parcels spatially dispersed in homogenous topography, in combination with or without agriculture intensification programs.

In order to empirically test and evaluate how farmland fragmentation can be best managed for food security motives, prior to the design of any policy and strategy in favor of either farmland fragmentation conservation or defragmentation (consolidation) or both 
as land management tools, this study recommends the identification of all the possible farmland fragmentation scenarios (forms, causes, and their positive and negative impacts) in a given area, and the conditions dictating their problematic and beneficial status quos. In this line, for the sake of assessing the problematic and rational farmland fragmentation forms and scenarios under distinctive local circumstances, a rigorous feasibility study should be conducted, before the development of their suitable, flexible (dynamic), desirable, climate resilient, sustainable, feasible and multidimensional food security responsive coping strategies, policies and interventions at the household and individual levels. Instead of the existing focus on food productivity at the community, regional and national levels, the efforts should be oriented towards the improvement of food security status at the household and individual levels and the consideration of agroecological approaches in local food production on either fragmented or consolidated land. Therefore, further research should focus on the scrutiny and the development of more detailed and comprehensive indicators which can facilitate the trade-offs between farmland fragmentation conservation and defragmentation policies and interventions for food security motives under various particular local contexts.

The novel insights of this study can inform and guide policy makers, research scholars and the general scientific community for the devise of the suitable policies, interventions, tools and strategies for the best management of local farmland fragmentation scenarios. Moreover, contrary to the existing popular and global logic favoring the market-oriented agriculture often combined with agriculture expansion on big consolidated farms to achieve food security, this novel knowledge about the necessity of the variety of farmland management instruments to address particular farmland fragmentation scenarios contributes to the achievement of the sustainable development goals (SDGs 1.4; 2.1,2,3,4 and 5; 12.2; 13.1; and 15.3,4,5 and 9) of ending hunger, malnutrition, and poverty in the framework of the agenda 2030. As stipulated by these SDGs specific targets, this can be possible through the diversification of crops in diverse fragmented and scattered areas with various crop-growing conditions; equal distribution, ownership, access and control, sustainable management and efficient use of land resources; and agrobiodiversity and ecosystems conservation on land as an adaptive strategy to the global climate change realities and challenges (through climate smart or resilient agriculture), often combined with agriculture intensification programs to increase the agriculture production of small farms (see Paragraph 6 of Section 1 for these specific SDGs targets), for food sovereignty and the household food security motives.

Author Contributions: Conceptualization, P.D.N. and W.T.d.V.; methodology, P.D.N.; software, P.D.N.; validation, P.D.N. and W.T.d.V.; formal analysis, P.D.N.; investigation, P.D.N.; resources, P.D.N.; data curation, P.D.N.; writing — original draft preparation, P.D.N.; writing-review and editing, W.T.d.V.; visualization, P.D.N.; supervision, W.T.d.V.; project administration, P.D.N.; funding acquisition, P.D.N. All authors have read and agreed to the published version of the manuscript.

Funding: This research received no special external funding. The Article Processing Charge (APC) was funded by the Technische Universitaet Muenchen (TUM) Open Access Publishing Fund.

Acknowledgments: The authors would like to acknowledge the Editors, anonymous reviewers and colleague research scholars who contributed to shaping and improving the quality of this review paper through their insightful comments. We are also grateful to the Katholischer Akademischer Auslaender Dienst (KAAD) and the Government of Rwanda through the Ministry of Education for their various supports towards the accomplishment of this research.

Conflicts of Interest: The authors declare no conflict of interest. The funders had no role in the design of the study; in the collection, analyses, or interpretation of data; in the writing of the manuscript, or in the decision to publish the results. 


\section{References}

1. Akkaya, A.S.T.; Kirmikil, M.; Gündoğdu, K.S.; Arici, I. Reallocation model for land consolidation based on landowners' requests. Land Use Policy 2018, 70, 463-470. [CrossRef]

2. Alemu, G.T.; Berhanie Ayele, Z.; Abelieneh Berhanu, A. Effects of Land Fragmentation on Productivity in Northwestern Ethiopia. Adv. Agric. 2017. [CrossRef]

3. Bizimana, C.; Nieuwoudt, W.L.; Ferrer, S.R. Farm size, land fragmentation and economic efficiency in southern Rwanda. Agrekon 2004, 43, 244-262. [CrossRef]

4. FAO. The Design of Land Consolidation Pilot Projects in Central and Eastern Europe; FAO: Rome, Italy, 2003; Volume 6, ISBN 9251050015. Available online: http:/ / www.fao.org/3/a-Y4954E.pdf (accessed on 20 April 2018).

5. Jürgenson, E. Land reform, land fragmentation and perspectives for future land consolidation in Estonia. Land Use Policy 2016, 57, 34-43. [CrossRef]

6. Kawasaki, K. The costs and benefits of land fragmentation of rice farms in Japan. Aust. J. Agric. Resour. Econ. 2010, 54, 509-526. [CrossRef]

7. Latruffe, L.; Piet, L. Does land fragmentation affect farm performance? A case study from Brittany, France. Agric. Syst. 2014, 129, 68-80. [CrossRef]

8. Niroula, G.S.; Thapa, G.B. Impacts and causes of land fragmentation, and lessons learned from land consolidation in South Asia. Land Use Policy 2005, 22, 358-372. [CrossRef]

9. Tan, S.; Heerink, N.; Qu, F. Land fragmentation and its driving forces in China. Land Use Policy 2006, 23, 272-285. [CrossRef]

10. Hiironen, J.; Riekkinen, K. Agricultural impacts and profitability of land consolidations. Land Use Policy 2016, 55, 309-317. [CrossRef]

11. Ntihinyurwa, P.D.; de Vries, W.T. Farmland fragmentation and defragmentation nexus: Scoping the causes, impacts, and the conditions determining its management decisions. Ecol. Indic. 2020, 119, 106828. [CrossRef]

12. Abubakari, Z.; Van der Molen, P.; Bennett, R.; Kuusaana, E.D. Land consolidation, customary lands, and Ghana's Northern Savannah Ecological Zone: An evaluation of the possibilities and pitfalls. Land Use Policy 2016, 54, 386-398. [CrossRef]

13. Demetriou, D.; Stillwell, J.; See, L. Land consolidation in Cyprus: Why is an Integrated Planning and Decision Support System required? Land Use Policy 2012, 29, 131-142. [CrossRef]

14. Keeler, M.E.; Skuras, D.G. Land fragmentation and consolidation policies in Greek agriculture. Geogr. Assoc. 1990, 75, 73-76. Available online: https:/ /www.jstor.org/stable/40571937 (accessed on 15 April 2018).

15. Louwsma, M.; Lemmen, C.; Hartvigsen, M.; Hiironen, J.; Du Plessis, J.; Chen, M.; Laarakker, P. Land Consolidation and Land Readjustment for Sustainable Development:the Issues to be Addressed. In Proceedings of the FIG Working Week, Surveying the World of Tomorrow-From Digitalisation to Augmented Reality, Helsinki, Finland, 29 May-2 June 2017; FIG: Lausane, Switzerland, 2017; p. 19. Available online: http://www.fig.net/resources/proceedings/fig_proceedings/fig2017/papers/p06g/ P06G_louwsma_lemmen_et_al_8973.pdf (accessed on 23 May 2019).

16. Vitikainen, A. An overview of land consolidation in Europe. Nord. J. Surv. Real Estate Res. 2004, 1, 124-136. Available online: https:/ /journal.fi/njs/article/view/41504 (accessed on 14 July 2019).

17. Asiama, K.; Bennett, R.; Zevenbergen, J.; Mano, A.D.S. Responsible consolidation of customary lands: A framework for land reallocation. Land Use Policy 2019, 83, 412-423. [CrossRef]

18. Van Dijk, T. Scenarios of Central European land fragmentation. Land Use Policy 2003, 20, 149-158. [CrossRef]

19. Hartvigsen, M.B. Land Reform and Land Consolidation in Central and Eastern Europe after 1989: Experiences and Perspectives. Ph.D.-Serien for Det Teknisk-Naturvidenskabelige Fakultet, Aalborg Universitet. Ph.D. Thesis, Aalborg Universitetsforlag, Aalborg, Denmark, 2015. [CrossRef]

20. Van der Molen, P.; Lemmen, C.; Van Dijk, T.; Uimonen, M. Introducing the subject of modern land consolidation and symposium report. In Modern Land Consolidation: Symposium in Volvic (Clermont-Ferrand), Proceedings of the Symposium on Modern Land Consolidation Conference Amenagement Foncier Moderne, Clermont-Ferrand France, 10-11 September 2004; FIG Commission 7; International Federation of Surveyors: Frederiksberg, Denmark, 2004; pp. 4-18. Available online: https:/ / research.utwente.nl/ en/publications/introducing-the-subject-of-modern-land-consolidation-and-symposiu (accessed on 11 June 2019).

21. Van Dijk, T. Land consolidation as Central Europe's panacea reassessed. In Modern Land Consolidation: Symposium in Volvic (Clermont-Ferrand), Proceedings of the Symposium on Modern Land Consolidation Conference Amenagement Foncier Moderne, ClermontFerrand France, 10-11 September 2004; International Federation of Surveyors: Frederiksberg, Denmark, 2004; pp. 31-50. Available online: http:/ / www.fig.net/commission7/ france_2004/papers_symp/ts_01_vandijk.pdf (accessed on 11 June 2019).

22. Bizoza, A.R.; Havugimana, J.M. Land use consolidation in Rwanda: A case study of Nyanza district, Southern province. Int. J. Sustain. Land Use Urban. Plan. 2013, 1, 64-75. Available online: https:/ /www.sciencetarget.com/Journal/index.php/IJSLUP/ index (accessed on 15 April 2018).

23. Kathiresan, A. Farm Land Use Consolidation in Rwanda; Assessment from the Perspectives of Agriculture Sector, Republic of Rwanda, Eds.; Ministry of Agriculture and Animal Resources, Republic of Rwanda: Kigali, Rwanda, 2012. Available online: https://www.minagri.gov. rw/fileadmin/user_upload/documents/agridocs/Farm_Land_Use_Consolidation_in_Rwanda.pdf (accessed on 15 April 2018).

24. Huggins, C. Consolidating Land, Consolidating Control: State-Facilitated 'Agricultural Investment' through the 'Green Revolution' in Rwanda; Working paper 16; Land Deal Politics Initiative (LDPI): The Hague, The Netherlands, 2013; pp. 1-26. Available online: https:/ / assets.publishing.service.gov.uk/media/57a08a28e5274a31e0000464/LDPI_WP_16.pdf (accessed on 15 April 2018). 
25. Mbonigaba, J.; Dusengemungu, L. Farm Land Use Consolidation-a Home Grown Solution for Food Security in Rwanda; Ministry of Agriculture and Animal Husbandry, Ed.; Rwanda Agricultural Board, Ministry of Agriculture and Animal Husbandry: Kigali, Rwanda, 2013; p. 8. Available online: https://www.academia.edu/download/55849911/Farm_Land_Use_Consolidation-_a_ Home_Grown_Solution_for_Food_Security_in_Rwanda.pdf (accessed on 18 April 2018).

26. Musahara, H.; Nyamulinda, B.; Bizimana, C.; Niyonzima, T. Land use consolidation and poverty reduction in Rwanda. In Proceedings of the 2014 Annual World Bank Conference on Land and Poverty: Integrating Land Governance into the Post-2015 Agenda: Harnassing Synergies for Implementation and Monitoring Impact, Washington, DC, USA, 24-27 March 2014; The World Bank: Washington, DC, USA, 2019. Available online: https://www.oicrf.org/documents/40950/43224/Land+use+ consolidation+and+poverty+reduction+in+Rwanda.pdf/d89771cb-b975-6f89-ac94-fb6a19fdc093 (accessed on 7 August 2019).

27. Nilsson, P. The Role of Land Use Consolidation in Improving Crop Yields among Farm Households in Rwanda. J. Dev. Stud. 2019, 55, 1726-1740. [CrossRef]

28. Asiama, K.; Bennett, R.; Zevenbergen, J. Land consolidation on Ghana's rural customary lands: Drawing from the Dutch, Lithuanian and Rwandan experiences. J. Rural Stud. 2017, 56, 87-99. [CrossRef]

29. Asiama, K.; Bennett, R.; Zevenbergen, J. Land Consolidation for Sub-Saharan Africa's Customary Lands: The Need for Responsible Approaches. Rural Dev. 2017, 5, 39-45. [CrossRef]

30. Bentley, J.W. Economic and Ecological Approaches to Land Fragmentation: In Defense of a Much-Maligned Phenomenon. Annu. Rev. Anthropol. 1987, 16, 31-67. [CrossRef]

31. Blarel, B.; Hazell, P.; Place, F.; Quiggin, J. The Economics of Farm Fragmentation: Evidence from Ghana and Rwanda. World Bank Econ. Rev. 1992, 6, 233-254. [CrossRef]

32. Chigbu, U.E.; Ntihinyurwa, P.D.; de Vries, W.T.; Ngenzi, E.I. Why Tenure Responsive Land-Use Planning Matters: Insights for Land Use Consolidation for Food Security in Rwanda. Int. J. Environ. Res. Public Health 2019, 16, 1354. [CrossRef]

33. Ntihinyurwa, P.D.; de Vries, W.T.; Chigbu, U.E.; Dukwiyimpuhwe, P.A. The positive impacts of farm land fragmentation in Rwanda. Land Use Policy 2019, 81, 565-581. [CrossRef]

34. Pritchard, M.F. Land, power and peace: Tenure formalization, agricultural reform, and livelihood insecurity in rural Rwanda. Land Use Policy 2013, 30, 186-196. [CrossRef]

35. King, R.; Burton, S. Structural change in agriculture: The geography of land consolidation. Prog. Geogr. 1983, 7, 471-501. [CrossRef]

36. Ali, D.A.; Deininger, K.; Ronchi, L. Costs and Benefits of Land Fragmentation: Evidence from Rwanda; Policy Research Working Papers of the World Bank Group; World Bank Group: Washington, DC, USA, 2015; p. 7290. [CrossRef]

37. Ciaian, P.; Guri, F.; Rajcaniova, M.; Drabik, D.; Gomez y Paloma, S. Land fragmentation and production diversification: A case study from rural Albania. Land Use Policy 2018, 76, 589-599. [CrossRef]

38. Di Falco, S.; Penov, I.; Aleksiev, A.; van Rensburg, T.M. Agrobiodiversity, farm profits and land fragmentation: Evidence from Bulgaria. Land Use Policy 2010, 27, 763-771. [CrossRef]

39. Molle, F.; Srijantr, T. Between concentration and fragmentation: The resilience of the land system in the Chao Phraya Delta. In Perspectives on Social Agricultural Change in the Chao Phraya Delta; White Lotus Press: Bangkok, Thailand, 2003; Volume 12, pp. 77-107. ISBN 9744800259. Available online: http://horizon.documentation.ird.fr/exl-doc/pleins_textes/divers15-08/01003 3857.pdf (accessed on 27 July 2019).

40. Sklenicka, P.; Salek, M. Ownership and soil quality as sources of agricultural land fragmentation in highly fragmented ownership patterns. Landsc. Ecol. 2008, 23, 299-311. [CrossRef]

41. Cholo, T.C.; Fleskens, L.; Sietz, D.; Peerlings, J. Land fragmentation, climate change adaptation, and food security in the Gamo Highlands of Ethiopia. Agric. Econ. 2019, 50, 39-49. [CrossRef]

42. Knippenberg, E.; Jolliffe, D.; Hoddinott, J. Land Fragmentation and Food Insecurity in Ethiopia. Policy Res. Work. Pap. World Bank Group 2018, 8559. [CrossRef]

43. Ciaian, P.; Guri, F.; Rajcaniova, M.; Drabik, D.; Paloma, S. Land Fragmentation, Production Diversification, and Food Security: A Case Study from Rural Albania. In Proceedings of the Land Economics/Use Conference, Milan, Italy, 9-14 August 2015; International Association of Agricultural Economists (IAAE): Toronto, ON, Canada, 2015; p. 28. [CrossRef]

44. Ciaian, P.; Miroslava, R.; Guri, F.; Zhllima, E.; Shahu, E. The impact of crop rotation and land fragmentation on farm productivity in Albania. Stud. Agric. Econ. 2018, 120, 116-125. [CrossRef]

45. Knippenberg, E.; Jolliffe, D.; Hoddinott, J. Land Fragmentation and Food Insecurity in Ethiopia. Am. J. Agric. Econ. 2020, 102, 1557-1577. [CrossRef]

46. Leventon, J.; Laudan, J. Local food sovereignty for global food security? Highlighting interplay challenges. Geoforum 2017, 85, 23-26. [CrossRef]

47. Wezel, A.; Herren, B.G.; Kerr, R.B.; Barrios, E.; Gonçalves, A.L.R.; Sinclair, F. Agroecological principles and elements and their implications for transitioning to sustainable food systems. A review. Agron. Sustain. Dev. 2020, 40, 1-13. [CrossRef]

48. Thomas, V.G.; Kevan, P.G. Basic principles of agroecology and sustainable agriculture. J. Agric. Environ. Ethics 1993, 6, 1-19. [CrossRef]

49. Ali, D.A.; Deininger, K. Is There a Farm-Size Productivity Relationship in African Agriculture? Evidence from Rwanda; Policy Research Working Papers of the World Bank Group; World Bank Group: Washington, DC, USA, 2014. [CrossRef] 
50. Kadigi, R.; Kashaigili, J.; Sirima, A.; Kamau, F.; Sikira, A.; Mbungu, W. Land fragmentation, agricultural productivity and implications for agricultural investments in the Southern Agricultural Growth Corridor of Tanzania (SAGCOT) region, Tanzania. J. Dev. Agric. Econ. 2017, 9, 26-36. [CrossRef]

51. De Vries, W.T.; Chigbu, U.E. Responsible land management-Concept and application in a territorial rural context. fub. Flächenmanag. Bodenordn. 2017, 2, 65-73. Available online: https://mediatum.ub.tum.de/1360258 (accessed on 23 July 2019 ).

52. Stigler, G.J. The economies of scale. J. Law Econ. 1958, 1, 54-71. [CrossRef]

53. Wertheimer, M. Gestalt Theory; Kegan Paul, Trench, Trubner \& Company: London, UK, 1938. [CrossRef]

54. Burchi, F.; De Muro, P. From food availability to nutritional capabilities: Advancing food security analysis. Food Policy 2016, 60, 10-19. [CrossRef]

55. Demont, M.; Jouve, P.; Stessens, J.; Tollens, E. Boserup versus Malthus revisited: Evolution of farming systems in northern Côte d'Ivoire. Agric. Syst. 2007, 93, 215-228. [CrossRef]

56. Desiere, S.; D’Haese, M. Boserup versus Malthus: Does population pressure drive agricultural intensification? Evidence from Burundi. In Proceedings of the 89th Annual Conference on Agricultural Economics Society, University of Warwick, Coventry, UK, 13-15 April 2015; Agricultural Economics Society: Banbury, UK, 2015. [CrossRef]

57. Teece, D.J. Economies of scope and the scope of the enterprise. J. Econ. Behav. Organ. 1980, 1, 223-247. [CrossRef]

58. Salvati, L.; Tombolini, I.; Gemmiti, R.; Carlucci, M.; Bajocco, S.; Perini, L.; Ferrara, A.; Colantoni, A. Complexity in action: Untangling latent relationships between land quality, economic structures and socio-spatial patterns in Italy. PLoS ONE 2017, 12, e0177853. [CrossRef]

59. Wim, T.; Ónega, L.F.; María, T.J.; Crecente, M.R. A Complexity perspective on institutional change: Dealing with land fragmentation in Galicia. Soc. Evol. Hist. 2015, 14, 77-107. Available online: https://www.sociostudies.org/journal/files/seh/2015_2/077 -107.pdf (accessed on 23 September 2019).

60. Norberg, J.; Cumming, G. Complexity Theory for a Sustainable Future; Columbia University Press: New York Chichester, NY, USA, 2008; ISBN 9780231508865.

61. Gunderson, L.H. Ecological resilience in theory and application. Annu. Rev. Ecol. Syst. 2000, 31, 425-439. [CrossRef]

62. Lengnick, L. Resilient Agriculture: Cultivating Food Systems for a Changing Climate; New Society Publishers: Gabriola Island, BC, Canada, 2015; p. 288. ISBN 9781550925784. Available online: https:/ / books.google.de/books?id=n-D0AgAAQBAJ (accessed on 29 September 2019).

63. Boserup, E. The Conditions of Agricultural Growth: The Economics of Agrarian Change under Population Pressure; Transaction Publishers, Rutgers: New Brunswick, NJ, USA; London, UK, 2011; ISBN 9780202307930.

64. Maxwell, S.; Smith, M. Household Food Security: Concepts, Indicators, Measurements: A Conceptual Review; International Fund for Agricultural Development: Rome, Italy, 1992; pp. 1-72. ISBN 9280620215.

65. Pinstrup-Andersen, P. Food security: Definition and measurement. Food Secur. 2009, 1, 5-7. [CrossRef]

66. Manjunatha, A.; Anik, A.R.; Speelman, S.; Nuppenau, E. Impact of land fragmentation, farm size, land ownership and crop diversity on profit and efficiency of irrigated farms in India. Land Use Policy 2013, 31, 397-405. [CrossRef]

67. Leroy, J.L.; Ruel, M.; Frongillo, E.A.; Harris, J.; Ballard, T.J. Measuring the Food Access Dimension of Food Security: A Critical Review and Mapping of Indicators. Food Nutr. Bull. 2015, 36, 167-195. [CrossRef] [PubMed]

68. Sen, A. Poverty and Famines: An Essay on Entitlement and Deprivation; Oxford University Press Inc.: New York, NY, USA, 1981; ISBN 0198284632.

69. FAO. World Food Summit: Rome Declaration on World Food Security and World Food Summit Plan of Action; FAO: Rome, Italy, 1996; Available online: http:/ / refhub.elsevier.com/S0264-8377(18)30887-1/sbref0095 (accessed on 15 April 2018).

70. Komatsuzaki, M. Agro-ecological Approach for Developing a Sustainable Farming and Food System. J. Dev. Sustain. Agric. 2011, 6, 54-63. [CrossRef]

71. UN. Transforming Our World: The 2030 Agenda for Sustainable Development; UN General Assembly: New York, NY, USA, 2015; Available online: www.un.org/en/development/desa/population/migration/generalassembly/docs/globalcompact/A_RES_ 70_1_E.pdf (accessed on 29 September 2019).

72. Torraco, R.J. Writing integrative literature reviews: Guidelines and examples. Hum. Resour. Dev. Rev. 2005, 4, 356-367. [CrossRef]

73. Torraco, R.J. Writing integrative literature reviews: Using the past and present to explore the future. Hum. Resour. Dev. Rev. 2016, 15, 404-428. [CrossRef]

74. Webster, J.; Watson, R.T. Analyzing the past to prepare for the future: Writing a literature review. Mis Q. 2002, 26, 13-23.

75. Ntihinyurwa, P.D.; de Vries, W.T. Farmland fragmentation concourse: Analysis of scenarios and research gaps. Land Use Policy 2021, 100, 104936. [CrossRef]

76. Snyder, H. Literature review as a research methodology: An overview and guidelines. J. Bus. Res. 2019, 104, 333-339. [CrossRef]

77. Langley, A. Strategies for Theorizing from Process Data. Acad. Manag. Rev. 1999, 24, 691-710. [CrossRef]

78. Klopper, R.; Lubbe, S.; Rugbeer, H. The matrix method of literature review. Alternation 2007, 14, 262-276. Available online: http:/ / alternation.ukzn.ac.za/Files / docs/14.1/12\%20Klopper\%20.pdf (accessed on 3 June 2019).

79. Salipante, P.; Notz, W.; Bigelow, J. A matrix approach to literature reviews. In Research in Organizational Behavior: An Annual Series of Analytical Essays and Critical Reviews; Elsevier: Amsterdam, The Netherlands, 1982; Volume 4, pp. 321-348.

80. McPherson, M.F. Land fragmentation: A selected literature review. In Development Discussion Paper; Harvard Institute for International Development, Harvard University: Cambridge, MA, USA, 1982; Volume 141. 
81. Iwasaki, Y. Reasoning with multiple abstraction models. In Recent Advances in Qualitative Physics; Faltings, B., Struss, P., Eds.; The MIT Press: London, UK, 1992; pp. 67-82. ISBN 0262061422. Available online: https://books.google.rw/books?hl= en\&lr=\&id=xmoSnz47ouUC\&oi=fnd\&pg=PA67\&ots=PT-3zwUmiB\&sig=iCRwC4Zr3E4Z1lWzZ5A76-G9Gi0\&redir_esc=y\#v= onepage\&q\&f=false (accessed on 27 October 2019).

82. Dhillon, L.; Vaca, S. Refining theories of change. J. Multidiscip. Eval. 2018, 14. Available online: https://pdfs.semanticscholar.org/ 6874/1e95cb3e6405fa114c00886f2d11cea2faff.pdf (accessed on 27 October 2019).

83. Lewis, M.W.; Grimes, A.J. Metatriangulation: Building theory from multiple paradigms. Acad. Manag. Rev. 1999, 24, 672-690. [CrossRef]

84. Boulding, K.E. General Systems Theory-The Skeleton of Science. Inf. Pubsonline 1956, 2, 197-208. [CrossRef]

85. Smith, L.B.; Thelen, E. A Dynamic Systems Approach to Development: Applications; Hardcover; The MIT Press: Cambridge, MA, USA, 1993; Volume 414, p. xviii. ISBN 0262193337.

86. Thelen, E. Dynamic Systems Theory and the Complexity of Change. Psychoanal. Dialogues 2005, 15, 255-283. [CrossRef]

87. Robinson, S.; Arbez, G.; Birta, L.G.; Tolk, A.; Wagner, G. Conceptual modeling: Definition, purpose and benefits. In Proceedings of the 2015 Winter Simulation Conference, Huntington Beach, CA, USA, 6-9 December 2015; IEEE Press: Piscataway, NJ, USA, 2015; pp. 2812-2826. [CrossRef]

88. Sabates-Wheeler, R. Consolidation initiatives after land reform: Responses to multiple dimensions of land fragmentation in Eastern European agriculture. J. Int. Dev. 2002, 14, 1005-1018. [CrossRef]

89. Binns, S.B.O. The Consolidation of Fragmented Agricultural Holdings; Food and Agriculture Organization of the United Nations(FAO): Rome, Italy, 1950; Volume 11.

90. McPherson, M.F. Land fragmentation in agriculture: Adverse? Beneficial? And for whom? In Development Discussion Paper; Harvard Institute for International Development, Harvard University: Cambridge, MA, USA, 1983; Volume 145, p. 81.

91. Simons, S. Land fragmentation in developing countries: The optimal choice and policy implications. In Proceedings of the 19th International Conference of Agricultural Economists, Malaga, Spain, 26 August-4 September 1985; International Association of Agricultural Economists: Milwaukee, WI, USA, 1985; pp. 703-716. Available online: https://ageconsearch.umn.edu/record/18 3032/ files/IAAE-CONF-228.pdf (accessed on 7 May 2018).

92. Dhakal, B.; Khanal, N. Causes and Consequences of Fragmentation of Agricultural Land: A Case of Nawalparasi District, Nepal. Geogr. J. Nepal 2018, 11, 95-112. [CrossRef]

93. Sundqvist, P.; Andersson, L. A Study of the Impacts of Land Fragmentation on Agricultural Productivity in Northern Vietnam. Bachelor's Thesis, Uppsala University, Uppsala, Sweden, 2006. Available online: http:/ /www.diva-portal.org/smash/get/diva2: 131275/FULLTEXT01.pdf (accessed on 13 July 2019).

94. Igbozurike, M.U. Fragmentation in tropical agriculture: An overrated phenomenon. Prof. Geogr. 1970, 22, 321-325. [CrossRef]

95. Brown, P.M.; Moyer, D.D. Multipurpose Land Information Systems: The Guidebook; Federal Geodetic Control Committee (FGCC): Rockville, NY, USA, 1994; Volume 2, Available online: https://books.google.rw/books?id=VG-avwEACAAJ (accessed on 14 July 2019).

96. Henssen, J. Land Registration and Cadastre Systems: Principles and Related Issues; Technische Universität München: Munich, Germany, 2010.

97. King, R.; Burton, S. Land fragmentation: Notes on a fundamental rural spatial problem. Prog. Geogr. 1982, 6, 475-494. [CrossRef]

98. Demetriou, D. The Development of an Integrated Planning and Decision Support System [IPDSS] for Land Consolidation. Ph.D. Thesis, University of Leeds: Leeds, UK; Springer International Publishing: Cham, Switzerland, 2014; Available online: http:/ / www.springer. $\mathrm{com} / \mathrm{series} / 8790$ (accessed on 14 May 2018).

99. Bullard, R. Land Consolidation and Rural Development; Home, R., Ed.; Papers in Land Management: No. 10; Anglia Ruskin University: Cambridge, UK; Chelmsford, UK, 2007; p. 148. Available online: http:/ / citeseerx.ist.psu.edu/viewdoc/download? doi=10.1.1.600.2529\&rep=rep1\&type=pdf (accessed on 17 June 2019).

100. Stroessner, G. Land consolidation in Bavaria: Support given to rural areas. J. Irrig. Eng. Rural Plan. 1986, 1986, 53-59. [CrossRef]

101. Meuser, F.J. European Expert Meeting on Land Consolidation, 1988. Analysis of the Results; Lehrstuhl fuer Bodenordnung und Landentwicklung der TU Muenchen: Muenchen, Germany, 1992; p. 195. Available online: http://agris.fao.org/agris-search/ search.do?recordID=DE94R0107 (accessed on 23 February 2020).

102. Magel, H. The change of paradigms in European rural development and land consolidation. Z. Fur Kult. Landentwickl. 2001, 42, 4-9. Available online: https://www.researchgate.net/publication/242280883_The_change_of_paradigms_in_European_rural_ development_and_land_consolidation (accessed on 23 February 2020).

103. Asiama, K.O.; Bennett, R.; Zevenbergen, J.; Asiama, S.O. Land valuation in support of responsible land consolidation on Ghana's rural customary lands. Surv. Rev. 2018, 50, 288-300. [CrossRef]

104. Lemmen, C.; Jansen, L.J.; Rosman, F. Informational and computational approaches to Land Consolidation. In Proceedings of the FIG Working Week: Knowing to Manage the Territory, Protect the Environment, Evaluate the Cultural Heritage, Rome, Italy, 6-10 May 2012; FIG: Lausane, Switzerland, 2012; p. 16. Available online: http:/ / www.fig.net/resources/proceedings / fig proceedings/fig2012/papers/ts02e/TS02E_lemmen_jansen_et_al_6049.pdf (accessed on 23 February 2020).

105. Vasiljevic, D.; Radulovic, B.; Babovic, M.; Todorović, S. Land Consolidation as Unused Potential: The Effects of Implementation, Barriers and Potential Relevance of Agricultural Land Consolidation in Serbia; Nacionalna Alijansa za Lokalni Ekonomski Razvoj: Belgrade, Serbia, 2018; ISBN 9788680128047. 
106. Zhang, X.; Ye, Y.; Wang, M.; Yu, Z.; Luo, J. The micro administrative mechanism of land reallocation in land consolidation: A perspective from collective action. Land Use Policy 2018, 70, 547-558. [CrossRef]

107. Sonnenberg, J. Fundamentals of land consolidation as an instrument to abolish fragmentation of agricultural holdings. In Proceedings of the FIG XXII International Congress, Washington, DC, USA, 19-26 April 2002; FIG: Lausane, Switzerland, 2002; pp. 1-12. Available online: http:// citeseerx.ist.psu.edu/viewdoc/download;jsessionid=B38B18AD2AABDA7FE7DC2DE424B79FA0 ?doi=10.1.1.489.4061\&rep=rep1\&type $=$ pdf (accessed on 30 January 2020).

108. Janus, J.; Łopacka, M.; John, E. Land consolidation in mountain areas. Case study from southern Poland. Geod. Cartogr. 2017, 66, 241-251. [CrossRef]

109. Hartvigsen, M. Land reform and land fragmentation in Central and Eastern Europe. Land Use Policy 2014, 36, 330-341. [CrossRef]

110. Cay, T.; Ayten, T.; Iscan, F. Effects of different land reallocation models on the success of land consolidation projects: Social and economic approaches. Land Use Policy 2010, 27, 262-269. [CrossRef]

111. FAO. Voluntary Guidelines on the Responsible Governance of Tenure of Land, Fisheries and Forests in the Context of National Food Security; FAO: Rome, Italy, 2012; p. 47. ISBN 9789251072776. Available online: http://www.fao.org/3/a-i2801e.pdf (accessed on 30 January 2020).

112. Thapa, G.B.; Niroula, G.S. Alternative options of land consolidation in the mountains of Nepal: An analysis based on stakeholders' opinions. Land Use Policy 2008, 25, 338-350. [CrossRef]

113. Zhang, B.; Niu, W.; Ma, L.; Zuo, X.; Kong, X.; Chen, H.; Zhang, Y.; Chen, W.; Zhao, M.; Xia, X. A company-dominated pattern of land consolidation to solve land fragmentation problem and its effectiveness evaluation: A case study in a hilly region of Guangxi Autonomous Region, Southwest China. Land Use Policy 2019, 88, 104115. [CrossRef]

114. Veršinskas, T.; Vidar, M.; Hartvigsen, M.; Mitic Arsova, K.; van Holst, F.; Gorgan, M. Legal Guide on Land Consolidation: Based on Regulatory Practices in Europe; FAO: Rome, Italy, 2020; Volume 3, p. 193. ISBN 9789251328583. [CrossRef]

115. Johansen, P.; Ejrnæs, R.; Kronvang, B.; Olsen, J.; Præstholm, S.; Schou, J. Pursuing collective impact: A novel indicator-based approach to assessment of shared measurements when planning for multifunctional land consolidation. Land Use Policy 2018, 73, 102-114. [CrossRef]

116. Haldrup, N.O. Agreement based land consolidation-In perspective of new modes of governance. Land Use Policy 2015, 46, 163-177. [CrossRef]

117. Ntihinyurwa, P.D.; Masum, F. Participatory Land Use Consolidation in Rwanda: From Principles to Practice. In Proceedings of the FIG Working Week: Surveying the World of Tomorrow_From Digitalisation to Augmented Reality, Helsinki, Finland, 29 May-2 June 2017; FIG: Lausane, Switzerland, 2017. Available online: https://www.fig.net/resources/proceedings/fig_ proceedings/fig2017/papers/ts04h/TS04H_ntihinyurwa_masum_9008.pdf (accessed on 25 June 2017).

118. Lerman, Z.; Cimpoieş, D. Land consolidation as a factor for rural development in Moldova. Eur. Asia Stud. 2006, 58, 439-455. [CrossRef]

119. USAID. Assessment of the Economic, Social, and Environmental Impacts of the Land Use Consolidation Component of the Crop Intensification Program in Rwanda; U.S. Agency for International Development(USAID/Rwanda), Democracy and Governance Office: Kigali, Rwanda, 2014; Available online: https: / / pdfs.semanticscholar.org/38dd/9d6c9d35e7b77ab59ca9431c581c91ceb3e9.pdf (accessed on 15 April 2018).

120. Laepple, E. Land Consolidation in Europe; 3-7843-2525-4; Schriftenreihe des Bundesministers fuer Ernaehrung, Landwirtschaft und Forsten, Reihe B: Flurbereinigung: Münster-Hiltrup, Germany, 1992; pp. 5-12.

121. Muyombano, E.; Espling, M. Land use consolidation in Rwanda: The experiences of small-scale farmers in Musanze District, Northern Province. Land Use Policy 2020, 99, 105060. [CrossRef]

122. Isaacs, K.B.; Snapp, S.S.; Chung, K.; Waldman, K.B. Assessing the value of diverse cropping systems under a new agricultural policy environment in Rwanda. Food Secur. 2016, 8, 491-506. [CrossRef]

123. Niyonzima, T. Land Use Dynamics in the Face of Population Increase: A Study in the Districts of Gatsibo and Nyagatare, Eastern Province, Rwanda. Ph.D. Thesis, School of Business, Economics and Law, Göteborg University, Göteborg, Sweden, 2009. Available online: https:/ / www.dissertations.se/dissertation/50a47cacc6/ (accessed on 5 July 2020).

124. Crecente, R.; Alvarez, C.; Fra, U. Economic, social and environmental impact of land consolidation in Galicia. Land Use Policy 2002, 19, 135-147. [CrossRef]

125. Damen, J. Land banking in The Netherlands in the Context of Land Consolidation. In Proceedings of the International Workshop: Land Banking/Land Funds as an Instrument for Improved Land Management for CEEC and CIS, Tonder, Denmark, 17-20 March 2004; FAO: Rome, Italy, 2004; pp. 1-5. Available online: http:/ / www.fao.org/fileadmin/user_upload/reu/europe/documents/ LANDNET/2004/Netherlands_paper.pdf (accessed on 26 June 2019).

126. Miranda, D.; Crecente, R. Suitability model for Land Consolidation projects: A case study in Galicia, Spain. In Proceedings of the Symposium on Modern Land Consolidation, Volvic (Clermont-Ferrand), France, 10-11 September 2004; FIG Commission 7. International Federation of Surveyors (FIG): Frederiksberg, Denmark, 2004; pp. 173-188. Available online: http://www.fig.net/ resources / proceedings/2004/france_2004_comm7/papers_symp/ts_04_miranda.pdf (accessed on 12 September 2019).

127. Van den Berg, R.; Revilla, E.; Menken, M.; Verbeek, I. Land Banking Principle: A Reconnaissance for Conditions and Practical Constrains for Application of the Land Banking Principle in the Netherlands; University of Wageningen: Wageningen, The Netherlands, 2005.

128. De Vries, W.T.; Wouters, R.; Konttinen, K. A comparative analysis of senior expert experiences with land consolidation projects and programs in Europe. In Proceedings of the FIG Working Week 2019, Geospatial Information for a Smarter Life and Environmental 
Resilience, Hanoi, Vietnam, 22-26 April 2019; FIG: Lausane, Switzerland, 2019. Available online: http:/ / www.fig.net/resources / proceedings/fig_proceedings/fig2019/papers/ts05h/TS05H_de_vries_wouters_et_al_9781.pdf (accessed on 15 May 2020).

129. Bentley, J.W. Wouldn't you like to have all of your land in one place? Land fragmentation in Northwest Portugal. Hum. Ecol. 1990, 18, 51-79. [CrossRef]

130. Farmer, B.H. On Not Controlling Subdivision in Paddy-Lands. Trans. Pap. 1960, 28, 225-235. [CrossRef]

131. Lisec, A.; Pintar, M. Conservation of natural ecosystems by land consolidation in the rural landscape. Acta Agric. Slov. 2005, 85 , 73-82. Available online: http:/ / citeseerx.ist.psu.edu/viewdoc/download?doi=10.1.1.476.23\&rep=rep1\&type=pdf $($ accessed on 11 March 2020).

132. Muchová, Z.; Petrovič, F. Changes in the landscape due to land consolidations. Ekológia 2010, 29, 140-157. [CrossRef]

133. Zhang, Q.-q.; Luo, H.-b.; Yan, J.-m. Integrating biodiversity conservation into land consolidation in hilly areas-A case study in southwest China. Acta Ecol. Sin. 2012, 32, 274-278. [CrossRef]

134. Van Dijk, T. Complications for traditional land consolidation in Central Europe. Geoforum 2007, 38, 505-511. [CrossRef]

135. Downing, T.E. Partible inheritance and land fragmentation in a Oaxaca village. Hum. Organ. 1977, 36, 235-243. [CrossRef]

136. Vander Meer, P. Land Consolidation through Land Fragmentation: Case Studies from Taiwan. Land Econ. 1975, 51, $275-283$. [CrossRef]

137. Lengoiboni, M.; Groenendijk, E.; Mukahigiro, A. Land tenure regularization in Rwanda: Registration of land rights for women and its impacts on food security. J. Land Adm. East. Afr. 2015, 3, 399-414. Available online: https://research.utwente. $\mathrm{nl}$ /en/publications/land-tenure-regularization-in-rwanda--registration-of-land-rights-for-women-and-its-impacts-on-foodsecurity(424ca5fd-a967-4cdb-afa8-218c985a3317).html (accessed on 15 April 2019).

138. Ntihinyurwa, P. An Evaluation of the Role of Public Participation in Land Use Consolidation (LUC) Practices in Rwanda and Its Improvement. Master's Thesis, Technical University of Munich, München, Germany, 2016.

139. Uwayezu, E.; de Vries, W.T. Scoping land tenure security for the poor and low-income urban dwellers from a spatial justice lens. Habitat Int. 2019, 91, 102016. [CrossRef]

140. Jia, L.; Petrick, M. How does land fragmentation affect off-farm labor supply: Panel data evidence from China. Agric. Econ. 2014, 45, 369-380. [CrossRef]

141. Lazíková, J.; Bandlerová, A.; Rumanovská, L.; Takáč, I.; Lazíková, Z. Crop Diversity and Common Agricultural Policy—The Case of Slovakia. Sustainability 2019, 11, 1416. [CrossRef]

142. Van der Molen, P. Food security, land use and land surveyors. Surv. Rev. 2017, 49, 147-152. [CrossRef]

143. Pijanowski, J.M. Land consolidation development-Disscusion of a new approach recommended for Poland. Geomat. Landmanag. Landsc. 2014, 2, 54-65. Available online: http://yadda.icm.edu.pl/yadda/element/bwmeta1.element.baztech-243d0e8b-74c1-409 d-b6f7-c85c6846fc7b / c GLL-2-2014f.pdf (accessed on 25 January 2020).

144. Burton, S.; King, R. Land fragmentation and consolidation in Cyprus: A descriptive evaluation. Agric. Adm. 1982, 11, 183-200. [CrossRef]

145. Brabec, E.; Smith, C. Agricultural land fragmentation: The spatial effects of three land protection strategies in the eastern United States. Landsc. Urban. Plan. 2002, 58, 255-268. [CrossRef]

146. Dam Lam, R.; Boafo, Y.A.; Degefa, S.; Gasparatos, A.; Saito, O. Assessing the food security outcomes of industrial crop expansion in smallholder settings: Insights from cotton production in Northern Ghana and sugarcane production in Central Ethiopia. Sustain. Sci. 2017, 12, 677-693. [CrossRef]

147. Ecker, O.; Breisinger, C. The Food Security System: A New Conceptual Framework; 01166; International Food Policy Research Institute (IFPRI), Development Strategy and Governance Division: Washington, DC, USA, 2012; p. 24. Available online: http:/ /cdm15738 .contentdm.oclc.org/utils/getfile/collection/p15738coll2/id/126837/filename/127048.pdf (accessed on 13 April 2019).

148. FAO. Global Strategic Framework for Food Security and Nutrition (GSF): "Making a difference in Food Security and Nutrition"; Committee on World Food Security (CFS): Rome, Italy, 2014; Volume 41, Available online: http:/ /www.fao.org/3/MR173EN/mr173en.pdf (accessed on 20 April 2020).

149. Maxwell, S. Food security: A post-modern perspective. Food Policy 1996, 21, 155-170. [CrossRef]

150. Pangaribowo, E.H.; Gerber, N.; Torero, M. Food and nutrition security indicators: A review. In ZEF Working Paper Series, No. 108; Econstor: Bonn, Germany, 2013; Available online: http:/ /hdl.handle.net/10419/88378 (accessed on 24 February 2020).

151. Weingärtner, L. The concept of food and nutrition security. In Achieving Food and Nutrition Security; 3rd ed.; Klennert, K., Ed.; InWEnt-Internationale Weiterbildung gGmbH: Feldafing, Germany, 2009; Volume 3, pp. 21-52. ISBN 9783939394570. Available online: http:/ / www.fao.org/docs/eims/upload/219148/food_reader_engl.pdf (accessed on 24 February 2020).

152. FAO. The State of Food Insecurity in the World; FAO \& World Food Program of the United Nations: Rome, Italy, $2009 ;$ p. 61. ISBN 9789251062883. Available online: http:/ / www.fao.org/docrep/pdf/012/i0876e/i0876e.pdf (accessed on 24 February 2020).

153. Campbell, C.C. Food Insecurity: A Nutritional Outcome or a Predictor Variable? J. Nutr. 1991, 121, 408-415. [CrossRef]

154. Holden, S.T.; Ghebru, H. Land tenure reforms, tenure security and food security in poor agrarian economies: Causal linkages and research gaps. Glob. Food Secur. 2016, 10, 21-28. [CrossRef]

155. TWN; SOCLA. Agroecology: Key Concepts, Principles and Practices; Third World Network (TWN) \& Sociedad Científica Latinoamericana de Agroecología (SOCLA): Penang, Malaysia, 2015; p. 54. ISBN 9789670747118. Available online: http:/ / foodfirst.org/wpcontent/uploads/2015/11/Agroecology-training-manual-TWN-SOCLA.pdf (accessed on 29 December 2020). 
156. Lake, I.; Abdelhamid, A.; Hooper, L.; Bentham, G.; Boxall, A.; Draper, A.; Fairweather-Tait, S.; Hulme, M.; Hunter, P.; Nichols, G. Food and Climate Change: A Review of the Effects of Climate Change on Food within the Remit of the Food Standards Agency; Food Standards Agency: London, UK, 2010. Available online: https://www.food.gov.uk/sites/default/files/media/document/575-11008_X02001_Climate_Change_and_Food_Report_28_Sept_2010.pdf (accessed on 25 June 2020).

157. Makate, C.; Wang, R.; Makate, M.; Mango, N. Crop diversification and livelihoods of smallholder farmers in Zimbabwe: Adaptive management for environmental change. SpringerPlus 2016, 5, 1135. [CrossRef]

158. Bailey, A. Mainstreaming Agrobiodiversity in Sustainable Food Systems: Scientific Foundations for an Agrobiodiversity Index-Summary; Bioversity International: Rome, Italy, 2016; ISBN 9789292550592. Available online: https://cgspace.cgiar.org/handle/10568/8036 0 (accessed on 25 June 2020).

159. Conceição, P.; Levine, S.; Lipton, M.; Warren-Rodríguez, A. Toward a food secure future: Ensuring food security for sustainable human development in Sub-Saharan Africa. Food Policy 2016, 60, 1-9. [CrossRef]

160. Fan, S.; Yosef, S.; Pandya-Lorch, R. Seizing the momentum to reshape agriculture for nutrition. In Agriculture for Improved Nutrition: Seizing the Momentum; eBook; CAB International: Wallingford, UK; International Food Policy and Research Institute (IFPRI): Washington, DC, USA, 2019; Volume 1, ISBN 9781786399328.

161. Lipper, L.; Thornton, P.; Campbell, B.M.; Baedeker, T.; Braimoh, A.; Bwalya, M.; Caron, P.; Cattaneo, A.; Garrity, D.; Henry, K. Climate-smart agriculture for food security. Nat. Clim. Chang. 2014, 4, 1068. [CrossRef]

162. Prasad, Y.; Maheswari, M.; Dixit, S.; Srinivasarao, C.; Sikka, A.; Venkateswarlu, B.; Sudhakar, N.; Prabhu Kumar, S.; Singh, A.; Gogoi, A. Smart Practices and Technologies for Climate Resilient Agriculture; Central Research Institute for Dryland Agriculture, Indian Council of Agricultural Research(ICAR): Hyderabad, India; New Delhi, India, 2014; p. 76. ISBN 9789380883304.

163. Rosegrant, M.W.; Cline, S.A. Global food security: Challenges and policies. Science 2003, 302, 1917-1919. [CrossRef] [PubMed]

164. Thornton, P.K.; Herrero, M. Adapting to climate change in the mixed crop and livestock farming systems in sub-Saharan Africa. Nat. Clim. Chang. 2015, 5, 830-836. [CrossRef]

165. FAO. The 10 Elements of Agroecology: Guiding the Transition to Sustainable Food and Agricultural Systems; FAO: Rome, Italy, 2018; p. 15. Available online: http:/ /www.fao.org/3/i9037en/i9037en.pdf (accessed on 29 December 2020).

166. Dudzińska, M.; Kocur-Bera, K. Assessment of land fragmentation for the purpose of land consolidation works as exemplified by the Pasym commune. Geomat. Land Manag. Landsc. 2014, 31-44. Available online: http://gll.ur.krakow.pl (accessed on 4 November 2019).

167. Edwards, C.J.W. The Effects of Changing farm size upon levels of farm Fragmentation: A Somerset Case Study. J. Agric. Econ. 1978, 29, 143-154. [CrossRef]

168. Papageorgiou, E. Fragmentation of land holdings and measures for consolidation in Greece. Land Tenure 1956, 543-547.

169. Rahman, S.; Rahman, M. Impact of land fragmentation and resource ownership on productivity and efficiency: The case of rice producers in Bangladesh. Land Use Policy 2009, 26, 95-103. [CrossRef]

170. Sikor, T.; Müller, D.; Stahl, J. Land fragmentation and cropland abandonment in Albania: Implications for the roles of state and community in post-socialist land consolidation. World Dev. 2009, 37, 1411-1423. [CrossRef]

171. Tan, S.; Heerink, N.; Kruseman, G.; Futian, Q. Do fragmented landholdings have higher production costs? Evidence from rice farmers in Northeastern Jiangxi province, PR China. China Econ. Rev. 2008, 19, 347-358. [CrossRef]

172. Van Hung, P.; MacAulay, T.G.; Marsh, S.P. The economics of land fragmentation in the north of Vietnam. Agric. Resour. Econ. 2007, 51, 195-211. [CrossRef]

173. Sargent, F.O. Fragmentation of French land: Its nature, extent, and causes. Land Econ. 1952, 28, 218-229. [CrossRef]

174. Grammatikopoulou, I.; Myyrä, S.; Pouta, E. The proximity of a field plot and land-use choice: Implications for land consolidation. J. Land Use Sci. 2013, 8, 383-402. [CrossRef]

175. Grigg, D.B. Population Growth and Agrarian Change: An Historical Perspective; CUP Archive: Cambridge, UK, 1980 ; ISBN 0521296358.

176. Galt, A.H. Exploring the cultural ecology of field fragmentation and scattering on the island of Pantelleria, Italy. J. Anthropol. Res. 1979, 35, 93-108. [CrossRef]

177. Netting, R. Of men and meadows: Strategies of alpine land use. Anthropol. Q. 1972, 45, 132-144. [CrossRef]

178. Mutangiza, O. The Contribution of Land Use Consolidation Policy to Food and Nutrition Security of Women Farmers: A Case Study of the Farmers Involved in Potato Farming, Food Availability in Nyabihu District, Rwanda. Master's Thesis, Sveriges Lantbruksuniversitet (SLU), Swedish University of Agricultural Sciences, Uppsala, Sweden, 2019. Available online: http: / / urn.kb.se/resolve?urn=urn:nbn:se:slu:epsilon-s-10458 (accessed on 17 March 2020).

179. Alexandri, C.; Luca, L.; Kevorchian, C. Subsistence Economy and Food Security-The Case of Rural Households from Romania. Procedia Econ. Financ. 2015, 22, 672-680. [CrossRef]

180. Reddy, P.P. Climate Resilient Agriculture for Ensuring Food Security; Springer: New Delhi, India, 2015; Volume 373, ISBN 9788132221999. [CrossRef]

181. Paul, M.; wa Gĩthĩnji, M. Small farms, smaller plots: Land size, fragmentation, and productivity in Ethiopia. J. Peasant Stud. 2018, 45, 757-775. [CrossRef]

182. Wan, G.H.; Cheng, E. Effects of land fragmentation and returns to scale in the Chinese farming sector. Appl. Econ. 2001, 33, 183-194. [CrossRef] 